\title{
Loss of Predominant Shank3 Isoforms Results in Hippocampus-Dependent Impairments in Behavior and Synaptic Transmission
}

\author{
Mehreen Kouser, ${ }^{1 \star}$ Haley E. Speed, ${ }^{1 \star}$ Colleen M. Dewey, ${ }^{1}$ Jeremy M. Reimers, ${ }^{1}$ Allie J. Widman, ${ }^{1}$ Natasha Gupta, ${ }^{1}$ \\ Shunan Liu, ${ }^{1}$ Thomas C. Jaramillo, ${ }^{1}$ Muhammad Bangash, ${ }^{3}$ Bo Xiao, ${ }^{3}$ Paul F. Worley, ${ }^{3}$ and Craig M. Powell ${ }^{1,2}$ \\ Departments of ${ }^{1}$ Neurology and Neurotherapeutics and ${ }^{2}$ Psychiatry, University of Texas Southwestern Medical Center, Dallas, Texas 75390-8813, and \\ ${ }^{3}$ Department of Neuroscience, Johns Hopkins University School of Medicine, Baltimore, Maryland 21205
}

\begin{abstract}
The Shank3 gene encodes a scaffolding protein that anchors multiple elements of the postsynaptic density at the synapse. Previous attempts to delete the Shank3 gene have not resulted in a complete loss of the predominant naturally occurring Shank 3 isoforms. We have now characterized a homozygous Shank3 mutation in mice that deletes exon 21, including the Homer binding domain. In the homozygous state, deletion of exon 21 results in loss of the major naturally occurring Shank3 protein bands detected by C-terminal and $\mathrm{N}$-terminal antibodies, allowing us to more definitively examine the role of Shank3 in synaptic function and behavior. This loss of Shank3 leads to an increased localization of mGluR5 to both synaptosome and postsynaptic density-enriched fractions in the hippocampus. These mice exhibit a decrease in NMDA/AMPA excitatory postsynaptic current ratio in area CA1 of the hippocampus, reduced long-term potentiation in area CA1, and deficits in hippocampus-dependent spatial learning and memory. In addition, these mice also exhibit motor-coordination deficits, hypersensitivity to heat, novelty avoidance, altered locomotor response to novelty, and minimal social abnormalities. These data suggest that Shank 3 isoforms are required for normal synaptic transmission/plasticity in the hippocampus, as well as hippocampus-dependent spatial learning and memory.
\end{abstract}

\section{Introduction}

Autism is characterized by differences in key behavioral domains: social behavior, language, and restricted and repetitive behaviors (Schreibman, 1988). Deletions and other loss-of-function mutations of the gene encoding the synaptic scaffolding protein SHANK3 have been strongly implicated in human autism (Durand et al., 2007; Moessner et al., 2007; Gauthier et al., 2009; Boccuto et al., 2012). Furthermore, there are hundreds of children with Phelan-McDermid syndrome (22q13 deletion syndrome, intellectual disability with autism or autistic features) in which SHANK3 is strongly implicated in the autistic features and broader neurodevelopmental phenotype (Bonaglia et al., 2001, 2006; Wilson et al., 2003; Dhar et al., 2010; Boccuto et al., 2012), making hemizygous SHANK3 deletion the most common

Received July 16, 2013; revised Sept. 20, 2013; accepted 0ct. 10, 2013.

Author contributions:M.K., H.E.S., J.M.R., and C.M.P. designed research; M.K., H.E.S., C.M.D., J.M.R., A.J.W., N.G., S.L., and T.C.J. performed research; M.B., B.X., and P.F.W. contributed unpublished reagents/analytic tools; M.K., H.E.S., C.M.D., J.M.R., A.J.W., N.G., and T.C.J. analyzed data; M.K., H.E.S., J.M.R., and C.M.P. wrote the paper.

${ }^{*}$ M.K. and H.E.S. contributed equally to this work.

This work was funded by National Institute of Child Health and Human Development Grants R01HD069560 (C.M.P.) and R01HD069560-0251 Diversity Supplement (T.C.J.), National Institute of Mental Health Grants R01MH093697 (C.M.P.) and P50MH084020 (P.F.W.), National Institute of Neurological Disorders and Stroke Grant R01NS070301 (P.F.W.), National Institute on Drug Abuse Grant T32DA007290 (J.M.R.), Autism Speaks (C.M.P.), Autism Science Foundation Postdoctoral Fellowship (H.E.S.), Autism Speaks Translational Postdoctoral Fellowship (H.E.S.), Autism Speaks Dennis Weatherstone Predoctoral Fellowship (M.K., M.A.B.), BRAINS for Autism (C.M.P.), The Hartwell Foundation (C.M.P.), and National 973 Basic Research Program of China Grant 20009 CB941400 (B.X.).

Correspondence should be addressed to Craig Powell at the above address. E-mail: craig.powell@utsouthwestern.edu. DOI:10.1523/JNEUROSCI.3017-13.2013

Copyright $\odot 2013$ the authors $\quad 0270-6474 / 13 / 3318448-21 \$ 15.00 / 0$
SHANK3 mutation associated with autistic features. Thus, a complete understanding of SHANK3 function in the CNS is critical to understand a subset of autism spectrum disorders caused by SHANK3 deletion or mutation.

Shank3 is a member of the Shank family of postsynaptic scaffolding proteins enriched in postsynaptic densities (PSDs) and was discovered in yeast two-hybrid screens as a binding partner of guanylate kinase-associated protein (GKAP) and postsynaptic density protein 95 (PSD-95; Naisbitt et al., 1999). Shank3 binds to the integral machinery of PSDs through its several functional domains. The ankyrin repeat domain of Shank3 mainly interacts with cytoskeletal proteins (Böckers et al., 2001). Its PSD protein/Drosophila disc large tumor suppressor/zonula occludens-1 protein (PDZ) domain interacts with ionotropic glutamate receptors either directly or indirectly via GKAP and PSD-95 (Garner et al., 2000; Uchino et al., 2006). The Homer binding domain of Shank3 binds to Homer, which then binds to the group 1 metabotropic glutamate receptors, such as mGluR1/5 (Tu et al., 1999).

Initial attempts to create mouse models lacking all Shank3 isoforms were unsuccessful, although they added important information of potential relevance to autism caused by SHANK3 mutations. Exon 4-9 or 4-7 deletion mouse models, coding for the ankyrin repeat domain, led to loss of only one of three major protein isoforms of Shank3 (Shank3 $\alpha$ ) by Western blot analysis (Bozdagi et al., 2010; Peça et al., 2011; Wang et al., 2011). A deletion model encompassing exons 13-16 (coding for the PDZ domain) led to loss of only two of the three major protein iso- 
forms of Shank3 (Shank $3 \alpha$ and Shank3 $\beta$; Peça et al., 2011) using a single antibody.

Interestingly, an exon 21 deletion (coding for the Homer binding domain) mouse model results in loss of the predominant naturally occurring isoforms of Shank3 in the homozygous state, providing an excellent model in which to understand the effects of loss of naturally occurring Shank3 isoforms. This exon 21 deletion mouse model is based on a particular autism-associated mutation in humans that involves a guanine nucleotide insertion in exon 21, creating a frame shift and premature stop codon near the Homer binding domain. In the hemizygous state $\left(\operatorname{Shank} 3^{+/ \Delta C}\right.$ ), this model results in only partial loss of the major naturally occurring Shank3 proteins (data not shown). In the homozygous state $\left(\right.$ Shank $3^{\Delta C / \Delta C}$ ), this model results in loss of major naturally occurring isoforms of Shank3 detected by N-terminal and C-terminal antibodies. Thus, examining the effects of homozygous mutation is informative of the function of Shank3, although only hemizygous mutation in exon 21 of the Shank 3 gene has been linked to autism.

In this study, we examine the biochemical, behavioral, and electrophysiological consequences of homozygous loss of major naturally occurring Shank3 isoforms in the exon 21 deletion mouse model. We find that Shank $3^{\Delta C / \Delta C}$ mice show deficits in spatial learning and memory, motor coordination, sensitivity to sensory stimuli, and responses to novelty. To begin to understand the underlying mechanisms of these deficits, we examine synaptic physiology in area CA1 of the hippocampus of these mice and find impairments in hippocampal synaptic transmission and plasticity. These findings highlight the importance of Shank3 in normal synaptic function and behavior and provide additional evidence of potential treatment targets for autism and intellectual disability associated with Shank3 deletion/mutation.

\section{Materials and Methods}

Generation of Shank $3^{\Delta C / \Delta C}$ mice. The Shank3 targeting construct was designed to delete exon 21 with Cre-mediated excision. To "flox" exon 21, Shank 3 bacterial artificial chromosome DNA clone (Geneservice) was modified using standard recombineering technology. The final targeting construct had two homology arms of 6.0 and $1.7 \mathrm{~kb}$, respectively. To identify targeted ES cells by PCR screen, a PCR control vector was constructed, which retains the Neo cassette and the short homology arm present in the targeting vector and additional Shank3 genomic sequence contiguous to the short arm. The targeting construct was electroporated into ES cells (129 s6 SvEv Tac background) and ES clones were selected for G418 resistance. The ES clones with targeted homologous recombination were identified by PCR with two sets of primers (forward, 50TCGCCTTCTTGACGAGTTCT; reverse, 50-ACACGCTTTGGACACT TCTC). The authenticity of desired homologous recombination in the ES clones was confirmed by sequencing the PCR products. The positive ES clones were then injected into blastocysts (C57BL/6 strain) to generate chimeras at the Transgenic Facility of Johns Hopkins University School of Medicine. The chimeric mice were bred with C57BL/6 mice to confirm germ-line transmission of floxed Shank3, which was identified by PCR with primers as follows: forward, 50-ACTTCGTATAATGTATGCTATACGAAG; reverse, 50-GGCCATTGAATGGCTTCTCTGG. The floxed Shank3 mice were then mated with mice expressing actin-cre to excise exon 21 . The resulting progeny were genotyped using a combination of three primers. The primer sequences were as follows: 50-TCCT GTGTCCCCTCATTGATGTT, 50-CTCTGCCACCTTCTGCCTACAA A, and 50-TGTCCTGTTGCAGGTAGGGAGAG. After confirming excision, the Shank $3^{+/ \Delta C}$ mice were mated with wild-type (WT) C57BL/6 mice to cross out the cre allele, and the progeny were further backcrossed with C57BL/6 mice for at least five generations. All mice tested were sex-matched, littermate progeny of matings between heterozygous Shank3 mutant mice. Overall, the Shank $3^{\Delta C / \Delta C}$ mutant mice appeared healthy except for their smaller body weight (measured at $\sim 17$ weeks of age; Shank ${ }^{\Delta C / \Delta C}, 24.57 \pm 0.13 \mathrm{~g} ; \mathrm{WT}, 31.95 \pm 0.15 \mathrm{~g} ; p<$ 0.001 ; Table 1).

Western blot. Synaptic protein levels from seven pairs (WT/Shank $3^{\Delta C / \Delta C}$, 5-6 months old) were determined by immunoblotting whole hippocampus dissected in ice-cold artificial CSF [ACSF; $124 \mathrm{~mm} \mathrm{NaCl}, 5 \mathrm{~mm} \mathrm{KCl}$, $1.25 \mathrm{~mm} \mathrm{NaH}_{2} \mathrm{PO}_{4}, 1 \mathrm{~mm} \mathrm{MgCl}_{2}, 26 \mathrm{~mm} \mathrm{NaHCO}_{3}, 10 \mathrm{~mm}$ dextrose, $2 \mathrm{~mm}$ $\mathrm{CaCl}_{2}, 5 \mathrm{~mm}$ EDTA, and $1 \times$ Halt protease and phosphatase inhibitor mixture (Thermo Fisher Scientific)] and then homogenized in 1\% SDS, $50 \mathrm{~mm} \mathrm{NaF}, 5 \mathrm{~mm}$ EDTA, and $1 \times$ Halt protease and phosphatase inhibitor mixture (Thermo Fisher Scientific). Ten micrograms of protein were loaded per lane and blotted with antibodies for synaptic proteins and internal loading controls ( $\beta$-actin). An Image Works film processor was used to develop films, and the chemiluminescence signals were quantified, normalized, and statistically analyzed using NIH ImageJ, Image Studio, and Microsoft Excel.

Synaptosome preparation. All steps were performed at $4^{\circ} \mathrm{C}$ or on ice; all buffers contained Halt protease and phosphatase inhibitors (Thermo Fisher Scientific). Mice were killed by live decapitation, and rapidly dissected hippocampi were homogenized in Syn-PER synaptic protein extraction reagent (Thermo Fisher Scientific), $\sim 1 \mathrm{ml} / 100 \mathrm{mg}$ tissue. Samples were centrifuged at $1200 \times g$ for $10 \mathrm{~min}$. The resulting supernatant was then centrifuged at $15,000 \times g$ for $20 \mathrm{~min}$. Pellets (synaptosomes) were resuspended in buffer B ( $3 \mathrm{~mm}$ sucrose in $6 \mathrm{~mm}$ Tris, $\mathrm{pH} 8.0$ ) with $1 \%$ SDS, briefly sonicated, and flash frozen in liquid nitrogen. Samples were stored at $-80^{\circ} \mathrm{C}$, and protein concentration was quantified by DC Protein Assay (Bio-Rad).

PSDII preparation. Synaptosome pellets were isolated as described above, resuspended in $1 \mathrm{ml}$ of buffer $\mathrm{B}$, and homogenized. Homogenates were gently layered onto sucrose density gradients $(1.15,1$, and $0.85 \mathrm{M}$ sucrose) and centrifuged at $82,500 \times g$. The fraction between 1.15 and 1 $\mathrm{M}$ sucrose layer was isolated, resuspended in buffer $\mathrm{C}$ ( $6 \mathrm{~mm}$ Tris, $\mathrm{pH} 8.0$, $1 \%$ Triton X-100), and incubated for $15 \mathrm{~min}$ before centrifugation at $32,800 \times g$ for $20 \mathrm{~min}$. The pellets were resuspended in buffer D $(6 \mathrm{~mm}$ Tris, $\mathrm{pH}$ 8.0, 0.5\% Triton X-100) and incubated for $15 \mathrm{~min}$. After centrifugation for $1 \mathrm{~h}$ at $201,800 \times g$, the resulting pellets (PSD-II) were resuspended in a minimal volume of buffer $\mathrm{D}$ and flash frozen in liquid nitrogen.

Behavioral overview. Behavioral tests were performed on a cohort of 9 female and 10 male, age- and sex-matched littermate pairs $(n=19 \mathrm{WT}$ and $n=19$ homozygous mutant) during the light cycle of the mice. All mice were born within 10 weeks of each other. Behaviors were tested at 2-6 months of age (unless otherwise noted) by an experimenter blind to genotype in the following order: elevated plus maze, dark/light, open field, locomotor, grooming, three-box social interaction test, marble burying, rotarod, social interaction with a juvenile, nesting behavior, Morris water maze, visible water maze, paired-pulse inhibition, startle threshold, footshock sensitivity, and hotplate sensitivity. One littermate pair was excluded from the analysis of elevated plus maze and social interaction with a juvenile as one littermate jumped out of the apparatus. Similarly, two littermate pairs were excluded from the three-box social interaction test as the mice climbed out and began circling the outer edge of the apparatus. Also, one mouse was found dead in its home cage on the morning after nesting behavior was performed, so its littermate pair was excluded from the study after nesting behavior. Ultrasonic vocalizations (USVs) emitted by male mice in the presence of a free-roaming estrous female were recorded in eight male age-matched littermate pairs at $10-13$ months of age. Afterward, grooming behavior was repeated in a cohort of seven male and an additional nine female littermate pairs $(n=$ $16 \mathrm{WT}$ and $n=16$ homozygous mutant).

Behavioral results are not described in the order they were tested in an effort to ease presentation and interpretation of the data. All statistical analyses of behavioral data were conducted using Statistica software (version 5.5; Statsoft) using either two-way ANOVAs or three-way repeatedmeasures ANOVA (rmANOVA) using genotype and sex as the main variables and trial as the repeated measure when applicable. Post hoc planned comparisons were applied for significant effects and interactions. For detailed information and numerical statistical results, see Table 1.

Morris water maze. The Morris water maze task was conducted essentially as described previously (Powell et al., 2004; Tabuchi et al., 2007). 
Table 1. Statistical analysis of behavioral studies

\begin{tabular}{ll}
\hline Parameter & Comparison \\
\hline Body weight $(n=19)$ & Sex and genotype \\
$\begin{array}{l}\text { Open field }(n=19) \\
\text { Time in center }\end{array}$ & Sex and genotype \\
Frequency in center & Sex and genotype \\
Time in periphery & Sex and genotype \\
Frequency in periphery & Sex and genotype \\
Time in center/time in periphery & Sex and genotype \\
Distance traveled & Sex and genotype \\
Velocity & Sex and genotype \\
Dark/light box ( $n=19)$ & \\
Total activity & Sex and genotype \\
Time in light side & Sexated plus maze $(n=18)$ \\
Distance traveled & Sex and genotype \\
Velocity & Sex \\
Time ine in open arms/time in both arms in open/entries in both & Sex and genotype \\
\hline
\end{tabular}

Morris water maze-initial training $(n=18)$ Latency to reach platform

Percentage thigmotaxis

Distance traveled to platform

Average swim speed

Sex, genotype, and day

Sex, genotype, and day
Results

2-way ANOVA; main effect of sex: $F_{(1,34)}=25.47, p<0.00001$; main effect of genotype: $F_{(1,34)}=14.60, p<0.001$; sex $\times$ genotype interaction: $F_{(1,34)}=0.17, p=0.67$

2-way ANOVA; main effect of sex: $F_{(1,34)}=0.33, p=0.56$; main effect of genotype: $F_{(1,34)}=0.10, p=0.74$; sex $\times$ genotype interaction: $F_{(1,34)}=4.26, p<0.4$

2-way ANOVA; main effect of sex: $F_{(1,34)}=0.05, p=0.82$; main effect of genotype: $F_{(1,34)}=5.59, p<0.03$; sex $\times$ genotype interaction: $F_{(1,34)}=2.47, p=0.12$

2-way ANOVA; main effect of sex: $F_{(1,34)}=0.99, p=0.32$; main effect of genotype: $F_{(1,34)}=4.44, p<0.05$; sex $\times$ genotype interaction: $F_{(1,34)}=0.13, p=0.71$

2-way ANOVA; main effect of sex: $p<0.0004, F_{(1,34)}=0.86, p=0.36$; main effect of genotype: $F_{(1,34)}=15.83$; sex $\times$ genotype interaction: $F_{(1,34)}=1.19, p=0.28$

2-way ANOVA; main effect of sex: $F_{(1,34)}=0.14, p=0.70$; main effect of genotype: $F_{(1,34)}=0.003, p=0.95$; sex $\times$ genotype interaction: $F_{(1,34)}=3.34, p=0.07$ 2-way ANOVA; main effect of sex: $F_{(1,34)}=0.02, p=0.88$; main effect of genotype: $F_{(1,34)}=23.54, p<0.00003$; sex $\times$ genotype interaction: $F_{(1,34)}=0.04, p=0.83$

2-way ANOVA; main effect of sex: $F_{(1,34)}=0.02, p=0.88$; main effect of genotype: $F_{(1,34)}=23.42, p<0.00003$; sex $\times$ genotype interaction: $F_{(1,34)}=0.04, p=0.84$

2-way ANOVA; main effect of sex: $F_{(1,34)}=0.16, p=0.68$; main effect of genotype: $F_{(1,34)}=35.60, p<0.000002$; sex $\times$ genotype interaction: $F_{(1,34)}=0.0001$, $p=0.99$

2-way ANOVA; main effect of sex: $F_{(1,34)}=2.32, p=0.13$; main effect of genotype: $F_{(1,34)}=29.06, p<0.00006$; sex $\times$ genotype interaction: $F_{(1,34)}=3.47, p=0.071$ 2-way ANOVA; main effect of sex: $F_{(1,34)}=1.55, p=0.22$; main effect of genotype: $F_{(1,34)}=26.83, p<0.00002 ;$ sex $\times$ genotype interaction: $F_{(1,34)}=0.71, p=0.40$ 2-way ANOVA; main effect of sex: $F_{(1,34)}=0.002, p=0.96$; main effect of genotype: $F_{(1,34)}=21.08, p<0.00006$; sex $\times$ genotype interaction: $F_{(1,34)}=0.006, p=0.93$ 2-way ANOVA; main effect of sex: $F_{(1,34)}=2.32, p=0.14$; main effect of genotype: $F_{(1,34)}=29.06, p<0.00006 ;$ sex $\times$ genotype interaction: $F_{(1,34)}=3.47, p=0.07$

2-way ANOVA; main effect of sex: $F_{(1,32)}=0.01, p=0.90$; main effect of genotype: $F_{(1,32)}=0.05, p=0.82$; sex $\times$ genotype interaction: $F_{(1,32)}=0.01, p=0.91$ 2-way ANOVA; main effect of sex: $F_{(1,32)}=0.14, p=0.70$; main effect of genotype: $F_{(1,32)}=0.48, p=0.49 ;$ sex $\times$ genotype interaction: $F_{(1,32)}=0.14, p=0.70$ 2-way ANOVA; main effect of sex: $F_{(1,32)}=0.50, p=0.48$; main effect of genotype: $F_{(1,32)}=0.12, p=0.73$; sex $\times$ genotype interaction: $F_{(1,32)}=0.06, p=0.79$ 2-way ANOVA; main effect of sex: $F_{(1,32)}=3.78, p=0.06$; main effect of genotype: $F_{(1,32)}=3.07, p=0.08$; sex $\times$ genotype interaction: $F_{(1,32)}=0.48, p=0.49$

3-way rmANOVA; main effect of sex: $F_{(1,32)}=0.35, p=0.55$; main effect of genotype: $F_{(1,32)}=13.55, p<0.001$; main effect of day: $F_{(7,224)}=36.47, p<0.000001$; sex $\times$ genotype interaction: $F_{(1,32)}=0.12, p=0.72$; sex $\times$ day interaction: $F_{(7,224)}=$ $1.58, p=0.14$; genotype $\times$ day interaction: $F_{(7,224)}=2.54, p<0.05$; sex $\times$ genotype $X$ day interaction: $F_{(7,224)}=0.53, p=0.806$

3-way rmANOVA; main effect of sex: $F_{(1,32)}=0.49, p=0.49$; main effect of genotype: $F_{(1,32)}=7.62, p<0.01$; main effect of day: $F_{(7,224)}=75.09, p<0.000001$; $\operatorname{sex} \times$ genotype interaction: $F_{(1,32)}=0.07, p=0.79 ;$ sex $\times$ day interaction: $F_{(7,224)}=$ $5.09, p<0.0001$; genotype $\times$ day interaction: $F_{(7,224)}=2.41, p<0.05$; sex $\times$ genotype $\times$ day interaction: $F_{(7,224)}=2.10, p<0.05$

3-way rmANOVA; main effect of sex: $F_{(1,32)}=0.83, p=0.36$; main effect of genotype: $F_{(1,32)}=17.41, p<0.001$; main effect of day: $F_{(7,224)}=41.61, p<0.000001$; sex $\times$ genotype interaction: $F_{(1,32)}=2.39, p=0.13$; sex $\times$ day interaction: $F_{(7,224)}=$ $1.02, p=0.41$; genotype $\times$ day interaction: $F_{(7,224)}=3.25, p<0.005$; sex $\times$ genotype $X$ day interaction: $F_{(7,224)}=0.72, p=0.65$

3-way rmANOVA; main effect of sex: $F_{(1,32)}=3.51, p=0.07$; main effect of genotype: $F_{(1,32)}=0.5, p=0.48$; main effect of day: $F_{(7,224)}=2.00, p=0.05$; sex $\times$ genotype interaction: $F_{(1,32)}=5.48, p<0.02 ;$ sex $\times$ day interaction: $F_{(7,224)}=0.59$, $p=0.75$; genotype $\times$ day interaction: $F_{(7,224)}=0.92, p=0.48$; sex $\times$ genotype $\times$ day interaction: $F_{(7,224)}=1.12, p=0.34$

WT versus KO

Males versus females
Planned comparisons: females (WT vs K0): $p<0.05$; Males (WT vs K0): $p=0.22$

Planned comparisons: WT (M vs F): $p=0.74$ KO (M vs F): $p<0.0006$ 
Table 1. Continued

Parameter

Percentage time in quadrant

Average swim speed

Percentage thigmotaxis

Distance traveled

Morris water maze-reversal training $(n=18)$ Latency to reach platform

Percentage thigmotaxis

Distance traveled to platform

Average swim speed

Morris water maze-reversal probe $(n=18)$

Percentage time in quadrant

Comparison

Sex, genotype, and quadrant

WT versus $\mathrm{KO}$ within quadrants

Target versus other quads within WT

Target versus other platforms KO

Sex, genotype, and platform

WT versus $\mathrm{KO}$ within platforms

Target versus other platforms WT

Target versus other platforms KO

WT versus $K 0$

Males versus females

Sex and genotype

WT versus $\mathrm{KO}$

Males versus females

Sex and genotype

Sex and genotype

WT versus $\mathrm{KO}$

Males versus females

Sex, genotype, and day

Sex, genotype, and day

Sex, genotype, and day

Sex, genotype, and day

Sex, genotype, and quadrant
Results

3-way rmANOVA; main effect of sex: $F_{(1,32)}=0.91, p=0.34$; main effect of genotype: $F_{(1,32)}=0.22, p=0.63$; main effect of quadrant: $F_{(3,96)}=33.49, p<0.000001$; sex $\times$ genotype interaction: $F_{(1,32)}=3.64, p=0.06$; sex $\times$ quadrant interaction: $F_{(3,96)}=0.51, p=0.67$; genotype $\times$ quadrant interaction: $F_{(3,96)}=4.21, p<0.01$; sex $\times$ genotype $\times$ quadrant interaction: $F_{(3,96)}=0.63, p=0.59$

Planned comparisons: TargetNW quad: $p<0.01$; RightNE quad: $p=0.87$; LeftSW quad: $p=0.40 ;$ OppositeSE quad: $p<0.01$

Planned comparisons: TargetNW versus RightNE: $p<0.00001$; TargetNW versus LeftSW: $p<0.00001$; TargetNW versus OppositeSE: $p<0.00001$

Planned comparisons: TargetNW versus RightNE: $p<0.02$; TargetNW versus LeftSW: $p<0.02$; TargetNW versus 0ppositeSE: $p<0.0001$

3-way rmANOVA; main effect of sex: $F_{(1,32)}=1.59, p=0.21$; main effect of genotype: $F_{(1,32)}=0.01, p=0.91$; main effect of quadrant: $F_{(3,96)}=13.00, p<0.000001$; sex $\times$ genotype interaction: $F_{(1,32)}=8.39, p<0.01$; sex $\times$ quadrant interaction:

$F_{(3,96)}=1.30, p=0.27$; genotype $\times$ quadrant interaction: $F_{(3,96)}=2.13, p=0.10$; sex $\times$ genotype $\times$ quadrant interaction: $F_{(3,96)}=0.47, p=0.70$

Planned Comparisons: TargetNW quad: $p=0.27$; RightNE quad: $p=0.69$; LeftSW quad: $p=0.83 ;$ OppositeSE quad: $p<0.01$

Planned comparisons: TargetNW versus RightNE: $p<0.001$; TargetNW versus LeftSW: $p<0.01$; TargetNW versus 0ppositeSE: $p<0.0001$

Planned comparisons: TargetNW versus RightNE: $p=0.08$; TargetNW versus LeftSW: $p=0.08$; TargetNW versus OppositeSE: $p=0.052$

Planned comparisons: females (WT v sK0): $p=0.05$; males (WT v sK0): $p<0.05$

Planned comparisons: WT (M vs F): $p=0.25 ; \mathrm{KO}$ (M vs F): $p<0.007$

2-way ANOVA; main effect of sex: $F_{(1,32)}=2.51, p=0.12$; main effect of genotype: $F_{(1,32)}=0.03, p=0.84$; sex $\times$ genotype interaction: $F_{(1,32)}=5.17, p<0.01$

Planned comparisons: females (WT vs K0): $p=0.10$; males (WT vs K0): $p=0.12$

Planned comparisons: WT (M vs F): $p=0.62 ; \mathrm{KO}$ (M vs F): $p<0.05$

2-way ANOVA; main effect of sex: $F_{(1,32)}=1.42, p=0.24$; main effect of genotype: $F_{(1,32)}=5.45, p<0.01$; sex $\times$ genotype interaction: $F_{(1,32)}=0.03, p=0.84$

2-way ANOVA; main effect of sex: $F_{(1,32)}=2.52, p=0.12$; main effect of genotype: $F_{(1,32)}=0.03, p=0.86$; sex $\times$ genotype interaction: $F_{(1,32)}=5.12, p<0.05$

Planned comparisons: females (WT vs K0): $p=0.11$; males (WT vs K0): $p=0.12$

Planned comparisons: WT (M vs F): $p=0.63 ; \mathrm{KO}$ (M vs F): $p<0.02$

3-way rmANOVA; main effect of sex: $F_{(1,32)}=0.0000041, p=0.99$; main effect of genotype: $F_{(1,32)}=2.63, p=0.11$; main effect of day: $F_{(4,128)}=8.05, p<0.0009$; sex $\times$ genotype interaction: $F_{(1,32)}=1.21, p=0.27$; sex $\times$ day interaction: $F_{(4,128)}=$ $0.64, p=0.63$; genotype $\times$ day interaction: $F_{(4,128)}=1.69, p=0.15$; sex $\times$ genotype $X$ day interaction: $F_{(4,128)}=0.27, p=0.89$

3-way rmANOVA; main effect of sex: $F_{(1,32)}=0.50, p=0.48$; main effect of genotype: $F_{(1,32)}=2.29, p=0.13$; main effect of day: $F_{(4,128)}=1.50, p=0.20$; sex $\times$ genotype interaction: $F_{(1,32)}=0.39, p=0.53$; sex $X$ day interaction: $F_{(4,128)}=1.22$, $p=0.30$; genotype $\times$ day interaction: $F_{(4,128)}=0.57, p=0.68$; sex $\times$ genotype $\times$ day interaction: $F_{(4,128)}=0.77, p=0.54$

3-way rmANOVA; main effect of sex: $F_{(1,32)}=0.44, p=0.51$; main effect of genotype: $F_{(1,32)}=2.08, p=0.15$; main effect of day: $F_{(4,128)}=4.99, p<0.0009$; sex $\times$ genotype interaction: $F_{(1,32)}=0.01, p=0.89$; sex $\times$ day interaction: $F_{(4,128)}=$ $0.91, p=0.45$; genotype $\times$ day interaction: $F_{(4,128)}=2.64, p<0.05$; sex $\times$ genotype $X$ day interaction: $F_{(4,128)}=0.65, p=0.62$

3-way rmANOVA; main effect of sex: $F_{(1,32)}=2.48, p=0.12$; main effect of genotype: $F_{(1,32)}=0.006, p=0.93$; main effect of day: $F_{(4,128)}=1.08, p=0.36$; sex $\times$ genotype interaction: $F_{(1,32)}=3.05, p=0.09$; sex $X$ day interaction: $F_{(4,128)}=1.21$, $p=0.30$; genotype $\times$ day interaction: $F_{(4,128)}=0.68, p=0.60$; sex $\times$ genotype $X$ day interaction: $F_{(4,128)}=1.84, p=0.12$

3-way rmANOVA; main effect of sex: $F_{(1,32)}=0.71, p=0.40$; main effect of genotype: $F_{(1,32)}=0.83, p=0.36$; main effect of quadrant: $F_{(3,96)}=5.87, p<0.01$; sex $\times$ genotype interaction: $F_{(1,32)}=0.76, p=0.38$; sex $\times$ quadrant interaction: $F_{(3,96)}=$ $1.76, p=0.15$; genotype $\times$ quadrant interaction: $F_{(3,96)}=6.51, p<0.001$; sex $\times$ genotype $\times$ quadrant interaction: $F_{(3,96)}=0.59, p=0.61$ 


\begin{tabular}{|c|c|}
\hline Parameter & Comparison \\
\hline & WT versus $\mathrm{KO}$ within platforms \\
\hline & Target versus other platforms WT \\
\hline & Target versus other platforms $\mathrm{KO}$ \\
\hline \multirow[t]{4}{*}{ Number of platform crossings } & Sex, genotype, and platform \\
\hline & WT versus $K 0$ within platforms \\
\hline & Target versus other platforms WT \\
\hline & Target versus other platforms $\mathrm{KO}$ \\
\hline Average swim speed & Sex and genotype \\
\hline Percentage thigmotaxis & Sex and genotype \\
\hline Distance traveled & Sex and genotype \\
\hline \multicolumn{2}{|l|}{ Visible water maze $(n=18)$} \\
\hline Latency to platform & Sex and genotype \\
\hline Percentage thigmotaxis & Sex and genotype \\
\hline Distance traveled to platform & Sex and genotype \\
\hline Average swim speed & Sex and genotype \\
\hline \multicolumn{2}{|l|}{ Hotplate $(n=18)$} \\
\hline Time to lick shake hindpaw & Sex and genotype \\
\hline
\end{tabular}

Nesting behavior $(n=19)$

Increase in nest height

Increase in nest width

Three-choice interaction test- baseline $(n=17)$ Distance traveled

Sex and genotype

Velocity

Time spent sniffing

Three-choice interaction test- social preference $(n=17)$

Distance traveled

Sex and genotype

Velocity
Sex, genotype, and time

Sex and genotype

Sex, genotype, and interaction target (front vs back)

Effect of target (within each genotype)

Sex and genotype
Results

Planned comparisons: TargetSE quad: $p<0.001$; RightNE quad: $p=0.08$; LeftSW quad: $p=0.76 ;$ OppositeNW quad: $p<0.01$

Planned comparisons: TargetSE versus RightNE: $p<0.001$; TargetSE versus LeftSW: $p<0.001$; TargetSE versus OppositeNW: $p<0.0001$

Planned comparisons: TargetSE versus RightNE: $p=0.55$; TargetSE versus LeftSW: $p=0.32$; TargetSE versus OppositeNW: $p=0.60$

3-way rmANOVA; main effect of sex: $F_{(1,32)}=0.003, p=0.95$; main effect of genotype: $F_{(1,32)}=6.11, p<0.02$; main effect of quadrant: $F_{(3,96)}=4.93, p<0.01$; sex $\times$ genotype interaction: $F_{(1,32)}=0.63, p=0.43$; sex $\times$ quadrant interaction: $F_{(3,96)}=$ $0.35, p=0.78$; genotype $\times$ quadrant interaction: $F_{(3,96)}=1.98, p=0.12$; sex $\times$ genotype $\times$ quadrant interaction: $F_{(3,96)}=0.04, p=0.98$

Planned comparisons: TargetSE quad: $p<0.05$; RightNE quad: $p=0.39$; Left SW quad: $p=0.19 ; 0$ ppositeNW quad: $p=0.86$

Planned comparisons: TargetSE versus RightNE: $p<0.05$; TargetSE versus LeftSW: $p<0.01$; TargetSE versus OppositeNW: $p<0.01$

Planned comparisons: TargetSE versus RightNE: $p=0.66$; TargetSE versus LeftSW: $p=0.20$; TargetSE versus OppositeNW: $p=0.68$

2-way ANOVA; main effect of sex: $F_{(1,32)}=1.67, p=0.20$; main effect of genotype: $F_{(1,32)}=1.16, p=0.28 ; \operatorname{sex} \times$ genotype interaction: $F_{(1,32)}=3.13, p=0.08$

2-way ANOVA; main effect of sex: $F_{(1,32)}=0.49, p=0.48$; main effect of genotype: $F_{(1,32)}=1.32, p=0.25$; sex $\times$ genotype interaction: $F_{(1,32)}=1.04, p=0.31$

2-way ANOVA; main effect of sex: $F_{(1,32)}=1.72, p=0.19$; main effect of genotype: $F_{(1,32)}=1.12, p=0.29 ;$ sex $\times$ genotype interaction: $F_{(1,32)}=3.23, p=0.08$

2-way ANOVA; main effect of sex: $F_{(1,32)}=0.15, p=0.69$; main effect of genotype: $F_{(1,32)}=2.93, p=0.09 ;$ sex $\times$ genotype: $F_{(1,32)}=0.07, p=0.78$

2-way ANOVA; main effect of sex: $F_{(1,32)}=0.0008, p=0.97$; main effect of genotype: $F_{(1,32)}=0.98, p=0.32 ;$ sex $\times$ genotype: $F_{(1,32)}=0.04, p=0.82$

2-way ANOVA; main effect of sex: $F_{(1,32)}=0.82, p=0.36$; main effect of genotype: $F_{(1,32)}=3.34, p=0.07$; sex $\times$ genotype: $F_{(1,32)}=0.02, p=0.86$

2-way ANOVA; main effect of sex: $F_{(1,32)}=0.89, p=0.35$; main effect of genotype: $F_{(1,32)}=0.34, p=0.56$; sex $\times$ genotype: $F_{(1,32)}=0.12, p=0.72$

2-way ANOVA; main effect of sex: $F_{(1,32)}=0.68, p=0.41$; main effect of genotype: $F_{(1,32)}=4.38, p<0.05 ;$ sex $\times$ genotype: $F_{(1,32)}=0.97, p=0.33$

3-way rmANOVA; main effect of sex: $F_{(1,34)}=6.004, p<0.02$; main effect of genotype: $F_{(1,34)}=17.78, p<0.001$; main effect of trial: $F_{(2,68)}=17.44, p<0.0001$; $\operatorname{sex} \times$ genotype interaction: $F_{(1,34)}=7.57, p<0.01$; sex $\times$ trial interaction: $F_{(2,68)}=1.78$, $p=0.17$; genotype $\times$ trial interaction: $F_{(2,68)}=4.73, p<0.02$; sex $\times$ genotype $X$ trial interaction: $F_{(4,128)}=0.55, p=0.57$

3-way rmANOVA; main effect of sex: $F_{(1,34)}=3.77, p=0.06$; main effect of genotype: $F_{(1,34)}=17.06, p<0.001$; main effect of trial: $F_{(2,68)}=7.60, p<0.01$; sex $\times$ genotype interaction: $F_{(1,34)}=3.55, p=0.06$; sex $\times$ trial interaction: $F_{(2,68)}=1.84$, $p=0.16$; genotype $\times$ trial interaction: $F_{(2,68)}=6.00, p<0.004$; sex $\times$ genotype $\times$ trial interaction: $F_{(4,128)}=1.48, p=0.23$

2-way ANOVA: main effect of sex: $F_{(1,30)}=0.52, p=0.47$; main effect of genotype: $F_{(1,30)}=2.70, p=0.11 ;$ sex $\times$ genotype interaction: $F_{(1,30)}=0.0004, p=0.98$ 2-way ANOVA: main effect of sex: $F_{(1,30)}=0.43, p=0.51$; main effect of genotype: $F_{(1,30)}=2.36, p=0.13 ;$ sex $\times$ genotype interaction: $F_{(1,30)}=0.0023, p=0.96$

3-way rmANOVA: main effect of sex: $F_{(1,30)}=0.03, p=0.86$; main effect of genotype: $F_{(1,30)}=1.23, p=0.27$; main effect of target: $F_{(1,30)}=0.01, p=0.90$; sex $\times$ genotype interaction: $F_{(1,30)}=4.01, p=0.05$; sex $\times$ target interaction: $F_{(1,30)}=1.00$, $p=0.32$; genotype $\times$ target interaction: $F_{(1,30)}=0.06, p=0.80$; sex $\times$ genotype $\times$ target interaction: $F_{(1,30)}=0.20, p=0.65$

Planned comparisons; $\mathrm{A}: p=0.92 ; \mathrm{B}: p=0.79$

2-way ANOVA: main effect of sex: $F_{(1,30)}=3.57, p=0.06$; main effect of genotype: $F_{(1,30)}=2.68, p=0.11 ; \operatorname{sex} \times$ genotype interaction: $F_{(1,30)}=0.14, p=0.70$ 2-way ANOVA: main effect of sex: $F_{(1,30)}=1.30, p=0.26$; main effect of genotype: $F_{(1,30)}=1.53, p=0.22 ;$ sex $\times$ genotype interaction: $F_{(1,30)}=0.55, p=0.46$ 
Table 1. Continued

\begin{tabular}{|c|c|c|}
\hline Parameter & Comparison & Results \\
\hline \multirow[t]{3}{*}{ Interaction time } & $\begin{array}{l}\text { Sex, genotype, and interaction target (inani- } \\
\text { mate vs social) }\end{array}$ & $\begin{array}{l}\text { 3-way rmANOVA: main effect of sex: } F_{(1,30)}=0.23, p=0.63 \text {; main effect of genotype: } \\
F_{(1,30)}=2.95, p=0.09 ; \text { main effect of target: } F_{(1,30)}=20.81, p<0.0001 ; \text { sex } \times \\
\text { genotype interaction: } F_{(1,30)}=0.002, p=0.96 ; \text { sex } \times \text { target interaction: } F_{(1,30)}= \\
1.54, p=0.22 ; \text { genotype } \times \text { target interaction: } F_{(1,30)}=0.36, p=0.54 ; \text { sex } \times \\
\text { genotype } \times \text { target interaction: } F_{(1,30)}=0.55, p=0.46\end{array}$ \\
\hline & Effect of target within each genotype & Planned comparisons; $\mathrm{A}: p<0.01 ; \mathrm{B}: p<0.001$ \\
\hline & $\begin{array}{l}\text { Effect of gentoype (WT vs K0) within each } \\
\text { target }\end{array}$ & Planned comparisons; social target: $p=0.60$; inanimate: $p<0.01$ \\
\hline Distance traveled & Sex and genotype & $\begin{array}{l}\text { 2-way ANOVA: main effect of sex: } F_{(1,30)}=14.80, p<0.0005 \text {; main effect of genotype: } \\
F_{(1,30)}=0.87, p=0.35 \text {; sex } \times \text { genotype interaction: } F_{(1,30)}=0.13, p=0.71\end{array}$ \\
\hline Velocity & Sex and genotype & $\begin{array}{l}\text { 2-way ANOVA: main effect of sex: } F_{(1,30)}=15.90, p<0.0003 \text {; main effect of genotype: } \\
F_{(1,30)}=0.45, p=0.50 \text {; sex } \times \text { genotype interaction: } F_{(1,30)}=0.007, p=0.93\end{array}$ \\
\hline & Effect of target within each genotype & Planned comparisons; $\mathrm{A}: p<0.05 ; \mathrm{B}: p=0.60$ \\
\hline & Effect of gentoype (WT vs K0) within each & Planned comparisons; familiar target: $p=0.87$; novel: $p=0.23$ \\
\hline
\end{tabular}

Social interaction with juvenile $(n=18)$ Interaction time

Locomotor habituation $(n=19)$

Total beam breaks

First bin only

Stereodypy beam breaks

Ambulatory beam breaks

$\operatorname{Rotarod}(n=19)$

Time to fall off

Prepulse inhibition ( $n=18)$

Initial startle response

Second set startle response

Third set startle response target

Sex, genotype, and trial

Trial (initial vs recognition) within each genotype

Sex, genotype, and bin

Genotype and sex

Sex, genotype, and bin

Sex, genotype, and bin

WT versus $K 0$ within each gender Males versus females within each genotype

Sex and genotype

Sex and genotype

Sex and genotype 3-way rmANOVA; main effect of sex: $F_{(1,32)}=1.46, p=0.23$; main effect of genotype: $F_{(1,32)}=0.502, p=0.48$; main effect of trial: $F_{(1,32)}=138.76, p<0.000001$; $\operatorname{sex} \times$ genotype: $F_{(1,32)}=1.00, p=0.32$; sex $\times$ trial interaction: $F_{(1,32)}=0.008, p=0.92$; genotype $X$ trial interaction: $F_{(1,32)}=3.88, p=0.05$; sex $\times$ genotype $\times$ trial interaction: $F_{(1,32)}=1.175, p=0.28$

Planned comparisons; $\mathrm{A}: p<0.00001 ; \mathrm{B}: p<0.00001$

3-way rmANOVA; main effect of sex: $F_{(1,34)}=0.32, p=0.57$; main effect of genotype: $F_{(1,34)}=0.49, p=0.48$; main effect of trial: $F_{(7,782)}=41.30, p<0.000001$; sex $\times$ genotype interaction: $F_{(1,34)}=0.06, p=0.80$; $\operatorname{sex} \times$ trial interaction: $F_{(7,782)}=$ $1.09, p=0.34$; genotype $\times$ trial: $F_{(7,782)}=1.21, p=0.22$; sex $\times$ genotype $\times$ trial interaction: $F_{(7,782)}=0.88, p=0.61$

2-way ANOVA; main effect of sex: $F_{(1,34)}=2.28, p=0.14$; main effect of genotype: $F_{(1,34)}=4.43, p<0.05 ; \operatorname{sex} \times$ genotype interaction: $F=0.09, p=0.76$

3-way rmANOVA; main effect of sex: $F_{(1,34)}=0.45, p=0.50$; main effect of genotype: $F_{(1,34)}=1.99, p=0.16$; main effect of trial: $F_{(7,782)}=21.07, p<0.000001$; $\operatorname{sex} \times$ genotype interaction: $F_{(1,34)}=1.07, p=0.30$; sex $\times$ trial interaction: $F_{(7,782)}=$ $1.16, p=0.27$; genotype $\times$ trial: $F_{(7,782)}=0.72, p=0.81$; sex $\times$ genotype $\times$ trial interaction: $F_{(7,782)}=0.72, p=0.82$

3-way rmANOVA; main effect of sex: $F_{(1,34)}=1.03, p=0.31$; main effect of genotype: $F_{(1,34)}=2.07, p=0.15$; main effect of trial: $F_{(7,782)}=39.29, p<0.000001$; sex $\times$ genotype interaction: $F_{(1,34)}=0.001, p=0.96$; sex $\times$ trial interaction: $F_{(7,782)}=$ $1.07, p=0.36$; genotype $\times$ trial: $F_{(7,782)}=1.42, p=0.08$; sex $\times$ genotype $\times$ trial interaction: $F_{(7,782)}=0.89, p=0.60$

3-way rmANOVA; main effect of sex: $F_{(1,34)}=7.17, p<0.02$; main effect of genotype: $F_{(1,34)}=6.95, p<0.02$; main effect of trial: $F_{(7,238)}=11.71, p<0.000001$; sex $\times$ genotype interaction: $F_{(1,34)}=0.45, p=0.50 ;$ sex $\times$ trial interaction: $F_{(7,238)}=$ $0.51, p=0.82$; genotype $\times$ trial: $F_{(7,238)}=1.60, p=0.13$; sex $\times$ genotype $\times$ trial interaction: $F_{(7,238)}=1.88, p=0.07$

Planned comparisons: within females: $p<0.05$; within males: $p=0.162$

Planned comparisons: within WT: $p<0.05$; within K0: $p=0.164$

2-way ANOVA; main effect of sex: $F_{(1,32)}=0.15, p=0.69$; main effect of genotype: $F_{(1,32)}=0.04, p=0.83$; sex $\times$ genotype interaction: $F_{(1,32)}=0.12, p=0.72$

2-way ANOVA; main effect of sex: $F_{(1,32)}=0.01, p=0.91$; main effect of genotype: $F_{(1,32)}=0.01, p=0.89$; sex $\times$ genotype interaction: $F_{(1,32)}=0.08, p=0.77$ 2-way ANOVA; main effect of sex: $F_{(1,32)}=0.002, p=0.95$; main effect of genotype: $F_{(1,32)}=0.008, p=0.92$; sex $\times$ genotype interaction: $F_{(1,32)}=0.0, p=0.99$ 
Table 1. Continued

\begin{tabular}{|c|c|c|}
\hline Parameter & Comparison & Results \\
\hline Startle habituation & Sex, genotype, and trial & $\begin{array}{l}\text { 3-way rmANOVA; main effect of sex: } F_{(1,32)}=0.02, p=0.87 \text {; main effect of genotype: } \\
F_{(1,32)}=0.02, p=0.88 ; \text { main effect of trial: } F_{(2,64)}=6.16, p<0.03 ; \text { sex } \times \text { geno- } \\
\text { type interaction: } F_{(1,32)}=0.05, p=0.81 ; \text { sex } \times \text { decibel interaction: } F_{(2,64)}=1.13 \text {, } \\
p=0.32 ; \text { genotype } \times \text { decibel interaction: } F_{(2,64)}=0.09, p=0.90 ; \text { sex } \times \text { genotype } \\
\quad \times \text { decibel interaction: } F_{(2,64)}=0.81, p=0.44\end{array}$ \\
\hline \multirow[t]{3}{*}{ Prepulse inhibition } & Sex, genotype, and decibel & $\begin{array}{l}\text { 3-way rmANOVA; main effect of sex: } F_{(1,34)}=5.85, p<0.03 \text {; main effect of genotype: } \\
F_{(1,34)}=3.06, p=0.08 ; \text { main effect of trial: } F_{(2,64)}=54.86, p<0.0001 ; \text { sex } \times \\
\text { genotype interaction: } F_{(1,34)}=5.50, p<0.03 ; \text { sex } \times \text { trial interaction: } F_{(2,64)}=0.03 \\
p=0.96 ; \text { genotype } \times \text { trial interaction: } F_{(2,64)}=0.20, p=0.81 ; \text { sex } \times \text { genotype } \times \\
\text { trial interaction: } F_{(2,64)}=1.14, p=0.32\end{array}$ \\
\hline & WT versus $\mathrm{KO}$ & Planned comparisons: females (WT vs K0): $p<0.01$; males (WT vs K0): $p=0.65$ \\
\hline & Males versus females & Planned comparisons: WT (M vs F): $p=0.95 \mathrm{KO}$ (M vs F): $p<0.01$ \\
\hline
\end{tabular}

Startle threshold $(n=18)$

Startle response

Sex, genotype, and decibel

Sex and genotype

Number of marbles buried

Grooming (9-18 weeks old) ( $n=19)$

Time spent grooming

Number of bouts

Sex and genotype

Sex and genotype

Time per bout

Sex and genotype

Grooming (10-13 months old) $(n=16)$

Time spent grooming

Number of bouts

Sex and genotype

Sex and genotype

Sex and genotype

Time per bout

USVs ( $10-13$ months old $)(n=8)$

Latency to call

Number of calls

Genotype

Genotype 3-way rmANOVA; main effect of sex: $F_{(1,32)}=0.19, p=0.65$; main effect of genotype: $F_{(1,32)}=0.008, p=0.92$; main effect of trial: $F_{(5,160)}=34.95, p<0.0001$; sex $\times$ genotype interaction: $F_{(1,32)}=0.47, p=0.49$; sex $\times$ decibel interaction: $F_{(5,160)}=$ $0.25 p=0.93$; genotype $\times$ decibel interaction: $F_{(5,160)}=0.03, p=0.99$; sex $\times$ genotype $\times$ decibel interaction: $F_{(5,160)}=0.34, p=0.88$

2-way ANOVA; main effect of sex: $F_{(1,34)}=0.01, p=0.90$; main effect of genotype: $F_{(1,34)}=58.20, p<0.000001$; sex $\times$ genotype interaction: $F_{(1,34)}=0.19, p=0.66$

2-way ANOVA: main effect of sex: $F_{(1,34)}=2.04, p=0.16$; main effect of genotype: $F_{(1,34)}=0.36, p=0.54$; sex $\times$ genotype interaction: $F_{(1,34)}=0.03, p=0.85$ 2-way ANOVA: main effect of sex: $F_{(1,34)}=0.17, p=0.67$; main effect of genotype: $F_{(1,34)}=1.32, p=0.25$; sex $\times$ genotype interaction: $F_{(1,34)}=0.25, p=0.62$ 2-way ANOVA: main effect of sex: $F_{(1,34)}=1.92, p=0.17$; main effect of genotype: $F_{(1,34)}=0.44, p=0.50$; sex $\times$ genotype interaction: $F_{(1,34)}=0.88, p=0.35$

2-way ANOVA: main effect of sex: $F_{(1,28)}=0.62, p=0.43$; main effect of genotype: $F_{(1,28)}=4.69, p<0.04$; sex $\times$ genotype interaction: $F_{(1,28)}=1.61, p=0.21$

2-way ANOVA: main effect of sex: $F_{(1,28)}=1.13, p=0.29$; main effect of genotype: $F_{(1,28)}=1.86, p=0.18$; sex $\times$ genotype interaction: $F_{(1,28)}=0.53, p=0.47$

2-way ANOVA: main effect of sex: $F_{(1,28)}=1.60, p=0.21$; main effect of genotype: $F_{(1,28)}=6.00, p<0.03 ;$ sex $\times$ genotype interaction: $F_{(1,28)}=2.44, p=0.12$

1-way ANOVA; main effect of genotype: $F_{(1,14)}=0.14, p=0.71$

1-way ANOVA; main effect of genotype: $F_{(1,14)}=0.40, p=0.52$

For ANOVAs, between-subjects factors are generally sex and genotype, with repeated measures (day, time, or trial). $F_{\left(x_{y, y} y^{\prime}\right.} F$ ratio statistic is used to determine whether the variances in two independent samples are equal; $x, y$ are degrees of freedom. Degrees of freedom is a measure of the number of independent pieces of information on which the precision of a parameter estimate is based. $x$, Number of groups $-1 ; y$, number of animals per group -1 , multiplied by the number of groups.

Briefly, a white, circular pool $1.2 \mathrm{~m}$ in diameter was filled with water $\left(22 \pm 1{ }^{\circ} \mathrm{C}\right)$ made opaque with nontoxic, "gothic white" liquid tempera paint, and a circular platform (10 cm in diameter) was submerged $\sim 1 \mathrm{~cm}$ beneath the surface of the water. The testing room was well lit and filled with a number of extramaze cues. Training was conducted over 9 consecutive days with four trials/d using an intertrial interval of 1-1.5 min. Mice were placed pseudorandomly into each of four starting locations for each of four daily training trials. In each trial, mice swam until they found the hidden platform or were guided to it by the experimenter if not found within $60 \mathrm{~s}$. Mice remained on the platform for $15 \mathrm{~s}$ before being removed to the home cage. Daily data were averaged across the four trials. A probe trial was conducted on day 10; the hidden platform was removed, and mice were placed in the pool and allowed to swim for $60 \mathrm{~s}$. For reversal water maze training, training resumed the day after the probe trial for $5 \mathrm{~d}$ with the platform in the opposite quadrant of the maze; on day 6 after reversal, a second probe trial was administered. Data were analyzed using three-way rmANOVA with genotype and sex as betweensubject factors and trial days as a within-subject factor for training. For probe trials, quadrant or platform location was used as the within-subject factor.

Accelerating rotarod. Coordination and motor learning were tested using a rotarod essentially as described previously (Powell et al., 2004). Mice were placed on a stationary rotarod (IITC Life Sciences) in a well lit room that was then activated and accelerated from 0 to 45 revolutions/ min over $5 \mathrm{~min}$. The latency for mice to fall off the rod or take one revolution was measured. Trials were repeated four times with intertrial intervals of $30 \mathrm{~min}$ over a single day. Data were analyzed using three-way rmANOVA with genotype and sex as between-subject factors and trials as a within-subject factor.

Hotplate sensitivity. This test was performed as described previously (Powell et al., 2004; Blundell et al., 2010b). Mice were placed on a black, anodized plate that was held at a constant temperature of $52^{\circ} \mathrm{C}$ (IITC Life Sciences model 39 hotplate) covered with a Plexiglas enclosure. Mice were removed after the first hindpaw lick or after $30 \mathrm{~s}$ if no response was elicited. The plate was cleaned with water between mice and allowed to return to temperature. Data were analyzed using two-way ANOVA with genotype and sex as between-subject factors.

Nesting. Nesting behavior was performed in a well lit ( $\sim 80$ lux $)$ room by first habituating the mouse to a novel home cage with $\sim 1.5 \mathrm{~cm}$ of bedding for $15 \mathrm{~min}$, and then a cotton nestlet $(5.5 \times 5.5 \times 0.5 \mathrm{~cm})$ was put in the cage. Height and width of the nests were measured at 30,60 , and 90 min (Etherton et al., 2009). Data were analyzed using two-way ANOVA with genotype and sex as between-subject factors.

Marble burying. As described previously (Blundell et al., 2010b), 20 marbles were evenly placed around the edges of a novel home cage with 5 $\mathrm{cm}$ of bedding, and mice were given $30 \mathrm{~min}$ in the cage. After $30 \mathrm{~min}$, the 
number of marbles buried was recorded. A marble was defined as buried when $<25 \%$ of the marble was visible. The test room was well lit $(\sim 80$ lux). Data were analyzed using two-way ANOVA with genotype and sex as between-subject factors.

Dark/light. The dark/light test was performed as described previously (Powell et al., 2004). Briefly, the dark/light apparatus consisted of two chambers (each chamber was $25 \times 26 \mathrm{~cm}$ ), one brightly lit ( 2900 lux) and the other kept dark with a small door $(7 \times 7 \mathrm{~cm})$ separating the two. Mice were habituated for $2 \mathrm{~min}$ in the dark side, the door was opened, and then mice were allowed to move freely between the two sides for 10 min. Time spent in and the number of entries into each side were measured along with locomotor activity using photobeams monitored by Med PC IV data acquisition software. Data were analyzed using two-way ANOVA with genotype and sex as between-subject factors.

Elevated plus maze. Mice were placed in the center of a white Plexiglas elevated plus maze (each arm was $33 \mathrm{~cm}$ long and $5 \mathrm{~cm}$ wide, with 15-cm-high black Plexiglas walls on closed arms) and allowed to explore for $5 \mathrm{~min}$ (Powell et al., 2004). The test was conducted in dim white light $(\sim 7$ lux $)$. Mice were monitored using CleverSys TopScan Software, and time spent in and entries into the open and closed arms were measured. Data were analyzed using two-way ANOVA with genotype and sex as between-subject factors.

Open field. The open-field test was performed as described previously (Powell et al., 2004; Blundell et al., 2009), with the exception of the data acquisition software. Mice were monitored using CleverSys TopScan Software after being placed in a white plastic arena $(48 \times 48 \times 48 \mathrm{~cm})$ for $10 \mathrm{~min}$. Time spent in and number of entries into the center of the arena $(15 \times 15 \mathrm{~cm})$ were recorded in addition to locomotor activity. The test was conducted in dim white light ( $\sim 7$ lux $)$. Data were analyzed using two-way ANOVA with genotype and sex as between-subject factors.

Locomotor. Locomotor activity was tested by placing the mice in a fresh home cage with minimal bedding and monitoring their activity for $2 \mathrm{~h}$ using photobeams linked to computer data acquisition software (San Diego Instruments; Powell et al., 2004). The test was conducted in the dark. Three-way rmANOVA was used to analyze the data with genotype and sex as between-subject factors and time as a within-subject factor.

Three-chambered social approach. Social versus inanimate object preference and preference for social novelty analyses were performed in a three-chambered box with small openings connecting the chambers as described previously (Blundell et al., 2009) and based to a large extent on the original descriptions (Moy et al., 2004; Nadler et al., 2004). The test was conducted in dim white light ( $\sim 7$ lux $)$. The mouse behavior was monitored using CleverSys TopScan Software. This test consisted of three 10-min trials. During the first trial, the mouse was allowed to explore the entire apparatus with empty cages in each end-chamber. In the second trial, the mouse was free to choose between an inanimate cage and a caged, social target. For the third trial, the mouse was free to choose between a caged, novel social target versus a caged, familiar social target. Locations of empty cages and social targets were counterbalanced, and mice were placed back into the home cage for very brief intervals between trials. Data were analyzed using three-way mixed ANOVA with genotype and sex as between-subject factors and target as a within-subject factor.

Social learning. Social interaction with a juvenile and social learning were performed as described previously (Kwon et al., 2006). Mice were first habituated to a dimly lit testing room $(\sim 7$ lux $)$ for $20 \mathrm{~min}$. After the habituation period, an experimental adult mouse and a juvenile target were placed together in a fresh home cage with no bedding. Time spent interacting with the juvenile was recorded live by an observer blind to genotype for $2 \mathrm{~min}$. After $3 \mathrm{~d}$, the above procedure was repeated to assess social learning. Data were analyzed using three-way mixed ANOVA with genotype and sex as between-subject factors and test session as a withinsubject factor.

Prepulse inhibition and startle. As described previously (Blundell et al., 2010a), startle chambers (San Diego Instruments) were modified for mice and mounted atop a piezoelectric accelerometer that detected and transduced animal movements. Acoustic stimuli were delivered by highfrequency speakers mounted $33 \mathrm{~cm}$ above the cylinders. Animal movements were digitized and stored using computer software supplied by San Diego Instruments. From the onset of startle stimuli, 65 1-ms read- ings were recorded, and the amplitude of the startle responses was obtained in arbitrary units. Chambers were calibrated before each set of mice, and sound levels were monitored using a sound meter (Tandy). For prepulse inhibition (PPI), mice were subjected to five trial types in a 22 min session: pulse alone ( $40 \mathrm{~ms}, 120 \mathrm{~dB}$, white noise pulse), three different prepulse/pulse trials ( $20 \mathrm{~ms}$ prepulse of 4,8 , or $16 \mathrm{~dB}$ above background noise level of $70 \mathrm{~dB}$ preceded the $120 \mathrm{~dB}$ pulse by $100 \mathrm{~ms}$ onset-onset interval), and no stimulus. All trials were presented pseudorandomly with an average of $15 \mathrm{~s}(7-23 \mathrm{~s})$ between the 62 trials. Testing began with a 5 min acclimation to the cylinders, followed by four blocks of test trials. The first and last blocks consisted of six pulse-alone trials. Blocks 2 and 3 each contained six pulse-alone trials, five of each level of prepulse/pulse trials, and five no-stimulus trials. Data were analyzed for baseline startle amplitude (initial pulse-alone trials) and PPI (percentage decrease in startle amplitude for prepulse/pulse trials compared with pulse-alone trials).

For the startle reactivity test, eight presentations of six trial types were given in pseudorandom order: no stimulus, $80,90,100,110$, or $120 \mathrm{~dB}$ pulses. Mean startle amplitudes for each condition were calculated. Data were analyzed using three-way mixed ANOVA with genotype and sex as between-subject factors and trial as a within-subject factor.

Grooming. Mice were placed in a novel home cage without the bedding, and time spent grooming the face, head, or body was measured for $10 \mathrm{~min}$. Number of grooming bouts that lasted $>1 \mathrm{~s}$ was also recorded. Time per bout was calculated by dividing the total time spent grooming by the number of grooming bouts initiated. Each grooming parameter described above was then analyzed using a two-way ANOVA with genotype and sex as between-subject factors.

USV. The male adult mouse was placed in a sound-attenuated $(11.5 \times$ $11.5 \times 11.5$ inches) chamber with an estrous female mouse and allowed to freely interact for $5 \mathrm{~min}$ while recording USV calls (Scattoni et al., 2010). The chamber was cleaned between trials. The Ultrasound Microphone (Avisoft UltraSoundGate condenser microphone CM16/CMPA; Avisoft Bioacoustics) was set up to record from a range of $10-200 \mathrm{kHz}$. The microphone was placed $\sim 5$ inches above the floor through a hole in the back wall of the chamber. The recording software was set at default settings with a $250 \mathrm{kHz}$ sampling rate, 16 bit format with a $32 \mathrm{~ms}$ buffer. To analyze the calls, the sound file was then converted to a spectrogram using the Avisoft SASLab Pro software. To reduce background noise, 25 $\mathrm{kHz}$ was set as a lower cutoff frequency. The analysis involved counting of calls and finding latency to first call. Data were analyzed using one-way ANOVA with genotype as a between-subject factor.

Electrophysiology. Male mice were briefly anesthetized with isoflurane (Baxter Healthcare Corporation) and rapidly decapitated. Brains were quickly removed and submerged in ice-cold modified ACSF containing in the following (in mM): 75 sucrose, $87 \mathrm{NaCl}, 3 \mathrm{KCl}, 1.25 \mathrm{NaH}_{2} \mathrm{PO}_{4}, 7$ $\mathrm{MgSO}_{4}, 26 \mathrm{NaHCO}_{3}, 20$ dextrose, and $0.5 \mathrm{CaCl}_{2}$. Acute hippocampal slices $350-400 \mu \mathrm{m}$ thick were made using a vibrating microtome (Vibratome). A cut was made between CA3 and CA1 to reduce recurrent excitation of CA3 neurons. Slices were allowed to recover at $33^{\circ} \mathrm{C}$ for 30 min in normal ACSF (in mM: $124 \mathrm{NaCl}, 5 \mathrm{KCl}, 1.25 \mathrm{NaH}_{2} \mathrm{PO}_{4}, 1 \mathrm{MgCl}_{2}$, $26 \mathrm{NaHCO}_{3}, 10$ dextrose, and $2 \mathrm{CaCl}_{2}$ ) and slowly cooled to room temperature over a $45 \mathrm{~min}$ period before recording. All solutions were $\mathrm{pH} 7.4$ and saturated with $95 \% \mathrm{O}_{2} / 5 \% \mathrm{CO}_{2}$.

All recordings were performed at $33 \pm 0.5^{\circ} \mathrm{C}$, and all data were collected using Clampex (pClamp software suite version 10.2; Molecular Devices). Recordings were filtered at $1 \mathrm{kHz}$ and digitized at $10 \mathrm{kHz}$. CA3-CA1 synapses were stimulated by a $100 \mu$ s biphasic pulse through a monopolar tungsten microelectrode (FHC) placed 400-500 $\mu$ m laterally from the recording electrode. The distance between the recording electrode and the stimulating electrode was kept constant within these bounds. For extracellular electrophysiology. the recording electrode (1-3 $\mathrm{M} \Omega$ ) was filled with normal ACSF and placed in the stratum radiatium using a SZX7 dissecting microscope (Olympus) at $35 \times$ magnification. For whole-cell electrophysiology, the recording electrode (4-6 M $\Omega$ ) contained the following (in $\mathrm{mm}$ ): 110 Cs-methanesulfonate, $15 \mathrm{CsCl}, 8$ $\mathrm{NaCl}, 10$ tetraethylammonium-Cl, 2 EGTA, 10 HEPES, $3 \mathrm{~N}$-(2,6dimethylphenylcarbamoylmethyl)triethylammonium chloride (QX314), 2 ATP, and 0.3 GTP. CA1 neurons were visually selected under $80 \times$ 
magnification using an AxioExaminer D1 differential interference contrast microscope (Zeiss).

The majority of experiments were performed on postnatal day 13 (P13) to P16 male mice, except long-term plasticity [long-term potentiation (LTP) and mGluR-long-term depression (LTD)] experiments, which were evaluated in young adult male mice (3-4 or 6-8 weeks, as noted). Sample size for extracellular field recordings [input/output (I/O) curve, paired-pulse ratio (PPR), long-term plasticity] represents number of slices tested with one to two slices used per mouse. Response size was determined by fitting a straight line to the initial slope $(10-40 \%)$ of the field EPSP (fEPSP) using automated analysis in Clampfit (pClamp software suite version 10.2; Molecular Devices). For studies of LTP and PPR, stimulus intensity was set to generate $\sim 50 \%$ of the maximum fEPSP, as determined by the I/O curve. Stimulus intensity was set at $75-85 \%$ of the maximum fEPSP for mGluR-LTD experiments. I/O curves were performed in each slice immediately preceding each field recording, and stimulus intensity remained unchanged thereafter for the duration of the experiment.

Whole-cell patch-clamp recordings were performed in the presence of $100 \mu \mathrm{M}$ picrotoxin to block fast inhibitory transmission and began 5-10 min (NMDA/AMPA ratio) or 10-15 min [miniature EPSCs (mEPSCs)] after successful break-in. The NMDA/AMPA ratio was measured at $0.1 \mathrm{~Hz}$ and elicited no short-term plasticity. For primarily AMPA receptor (AMPAR)mediated EPSCs, holding potential was $-70 \mathrm{mV}$, and peak amplitude was measured 10-15 ms after stimulus onset. For primarily NMDAR-mediated EPSCs, holding potential was $+40 \mathrm{mV}$, and peak amplitude was measured $40-45 \mathrm{~ms}$ after stimulus onset. mEPSCs were recorded for $5 \mathrm{~min}$ at a holding potential of $-65 \mathrm{mV}$ in the presence of $1 \mu \mathrm{M}$ octahydro-12-(hydroxymethyl)-2-imino-5,9:7,10a-dimethano-10aH[1,3] dioxocino[6,5-d]pyrimidine4,7,10,11,12-pentol tetrodotoxin [tetrodotoxin (TTX)] to block evoked transmission. Recordings were rejected if holding current or series resistance varied $>25 \%$ during the recording. Sample size indicates total number of cells from no less than four mice per group. Raw data were analyzed using Clampfit (pClamp software suite version 10.2; Molecular Devices). GraphPad Prism was used for statistical analysis and graphing. Means are expressed as mean \pm SEM.

Histology. For histological studies, brains were dissected from 6- to 8 -week-old mice and processed for Golgi-Cox staining with the FD Rapid GolgiStain Kit (FD Neurotechnologies). After live decapitation, brains were quickly removed and rinsed in double-distilled water and then immersed into impregnation solution, which was then replaced with fresh impregnation solution after $24 \mathrm{~h}$ and stored in the dark at room temperature $\left(22-25^{\circ} \mathrm{C}\right)$. After 2 weeks, the brains were transferred to solution $\mathrm{C}$ and then shipped to FD Neurotechnologies within $48 \mathrm{~h}$. Serial $100 \mu \mathrm{m}$ cryostat sections were cut coronally through the brain containing the hippocampus and mounted on glass slides. Twenty CA1 neurons from the dorsal hippocampus were selected from five mice per genotype (WT and Shank $3^{\Delta C / \Delta C}$ ). Neurons were traced using NeuroLucida 3D neuron tracing software (MicroBrightField) at $100 \times$ magnification by an experimenter blind to experimental conditions. Sholl analysis was conducted using NeuroLucida 3D software to study dendritic branching by drawing concentric circles $30 \mu \mathrm{m}$ apart starting at $30 \mu \mathrm{m}$ from the center of the cell body. For spine density experiments, $30 \mu \mathrm{m}$ apical dendrite segments that did not have any interfering crossings were chosen at defined distances from the cell body $(0-30,30-60,60-90$, and $90-120 \mu \mathrm{m})$. Data from the four neurons from each mouse were averaged together before statistical analysis. Data were analyzed using twoway mixed ANOVA with genotype as between-subject factor and distance from the cell body as a within-subject factor.

Drugs. TTX, picrotoxin, QX-314, and (RS)-3,5-dihydroxyphenylglycine (DHPG) were obtained from Tocris Bioscience. Cs-methanesulfonate and $\mathrm{CsCl}$ were obtained from Sigma-Aldrich. All other reagents were obtained from Thermo Fisher Scientific.

\section{Results}

Homozygous Shank3 mutation results in loss of major Shank3 isoforms

To quantify the loss of Shank3 in Shank $3^{\Delta C / \Delta C}$ mice compared with WT littermate controls, we performed quantitative Western blot analysis using antibodies directed against Shank3 $\mathrm{C}$ terminus $\left(\mathrm{C}^{\prime}\right)$, $\mathrm{N}$ terminus $\left(\mathrm{N}^{\prime}\right)$, and the $\mathrm{SH} 3$ domain (SH3) on hippocampal lysates from 5 - to 6 -month-old mice $(n=7)$. Western blot analysis reveals that Shank $3^{\Delta C / \Delta C}$ mice have lost major Shank3 isoforms detected by the C-terminal, $\mathrm{SH} 3$ domain, and $\mathrm{N}$-terminal antibodies [Fig. $1 A$; Shank $3\left(\mathrm{C}^{\prime}\right): t_{(12)}=11.418, p<$ 0.0001; Shank3(SH3): $t_{(12)}=8.524, p<0.0001$; Shank3( $\left.\mathrm{N}^{\prime}\right)$ : $\left.t_{(12)}=5.244, p<0.001\right]$. Interestingly, we also observe the appearance of lower-molecular-weight $(<100 \mathrm{kDa})$ isoforms of Shank3 detected by the $\mathrm{SH} 3$ domain and the N-terminal antibodies in Shank $3^{\Delta C / \Delta C}$ hippocampus that are not substantially present in the WT controls [Fig. $1 B$; Shank3(SH3 band 1): $t_{(12)}=$ 8.199, $p<0.0001$; Shank3(SH3 band 2): $t_{(12)}=5.818, p<0.0001$; Shank3( $\mathrm{N}^{\prime}$ band 1): $t_{(12)}=11.303, p<0.0001$; Shank3( $\mathrm{N}^{\prime}$ band $\left.2): t_{(12)}=5.494, p<0.001\right]$. Figure $1 C$ depicts longer representative Western blots with each of the three antibodies for reference.

In addition to Shank3, we also probed for Shank1, Shank2, and multiple other PSD proteins and receptors that bind directly or indirectly to Shank3 to identify any compensatory effects of Shank3 loss from hippocampal lysates. We did not observe any changes in levels of PSD proteins or synaptic receptor subunits in whole hippocampal homogenates (Fig. $1 D, E$ ).

\section{Homozygous Shank3 mutants exhibit increased mGluR5 in synaptic fractions}

To determine the effects of a complete loss of Shank3 on the subcellular distribution of synaptic proteins, we isolated the synaptosome and postsynaptic density (PSDII) fractions of the hippocampus of Shank $3^{\Delta C / \Delta C}$ mice compared with WT littermate controls following established methods with modifications (Cohen et al., 1977). As in the whole hippocampal lysates, we found dramatic loss of all three Shank3 isoforms in the synaptosome fractions [Fig. 2A; Shank3( $\left.\mathrm{N}^{\prime}\right): t_{(12)}=5.514, p<0.001$; Shank3(C'): $t_{(12)}=7.929, p<0.001$; Shank3(SH3): $t_{(12)}=$ $11.552, p<0.001]$. We also detected the presence of lowermolecular-weight $(<100 \mathrm{kDa})$ isoforms of Shank3 in synaptosomes using the N-terminal antibody [Fig. $2 B$; Shank3( $\mathrm{N}^{\prime}$ band $1): t_{(12)}=5.417, p<0.001$; Shank3( $\mathrm{N}^{\prime}$ band 2$): t_{(12)}=2.81256$, $p=0.016]$. Similar loss of Shank3 isoforms was observed in the PSDII fractions [Fig. $2 C$; Shank3 $\left(\mathrm{N}^{\prime}\right): t_{(4)}=9.82, p<0.001$; Shank3 $\left(\mathrm{C}^{\prime}\right): t_{(4)}=3.575, p=0.023$ ] along with the presence of lower-molecular-weight isoforms of Shank3 in PSDs [Fig. 2D; Shank3( $\mathrm{N}^{\prime}$ band 1): $t_{(4)}=6.594, p=0.003$; Shank3( $\mathrm{N}^{\prime}$ band 2): $\left.t_{(4)}=4.114, p=0.015\right]$ using the N-terminal antibody, suggesting that these lower-molecular-weight isoforms are present at hippocampal synapses.

In addition to Shank3, we analyzed the levels of synaptic proteins and receptors that are either directly or indirectly bound to Shank3 in the hippocampus. Strikingly, a significant increase in mGluR5 was seen in the synaptosome fraction (Fig. $2 A ; t_{(12)}=$ 5.867, $p<0.001)$ and to an even greater extent in the PSDII fraction (Fig. $2 C ; t_{(4)}=5.465, p=0.005$ ), suggesting enhanced mGluR5 localization to hippocampal synapses. We found no significant differences in ionotropic glutamate receptor subunits (NMDA or AMPA) or in other scaffolding and linker proteins (Fig. $2 A, C$ ) in the hippocampus of Shank $3^{\Delta C / \Delta C}$ mice.

\section{Homozygous Shank3 mutants are impaired in spatial learning}

Because $40-50 \%$ of autism patients exhibit intellectual disability (Wingate et al., 2012) and a majority of patients with SHANK3 mutation/deletion exhibit some degree of intellectual disability 

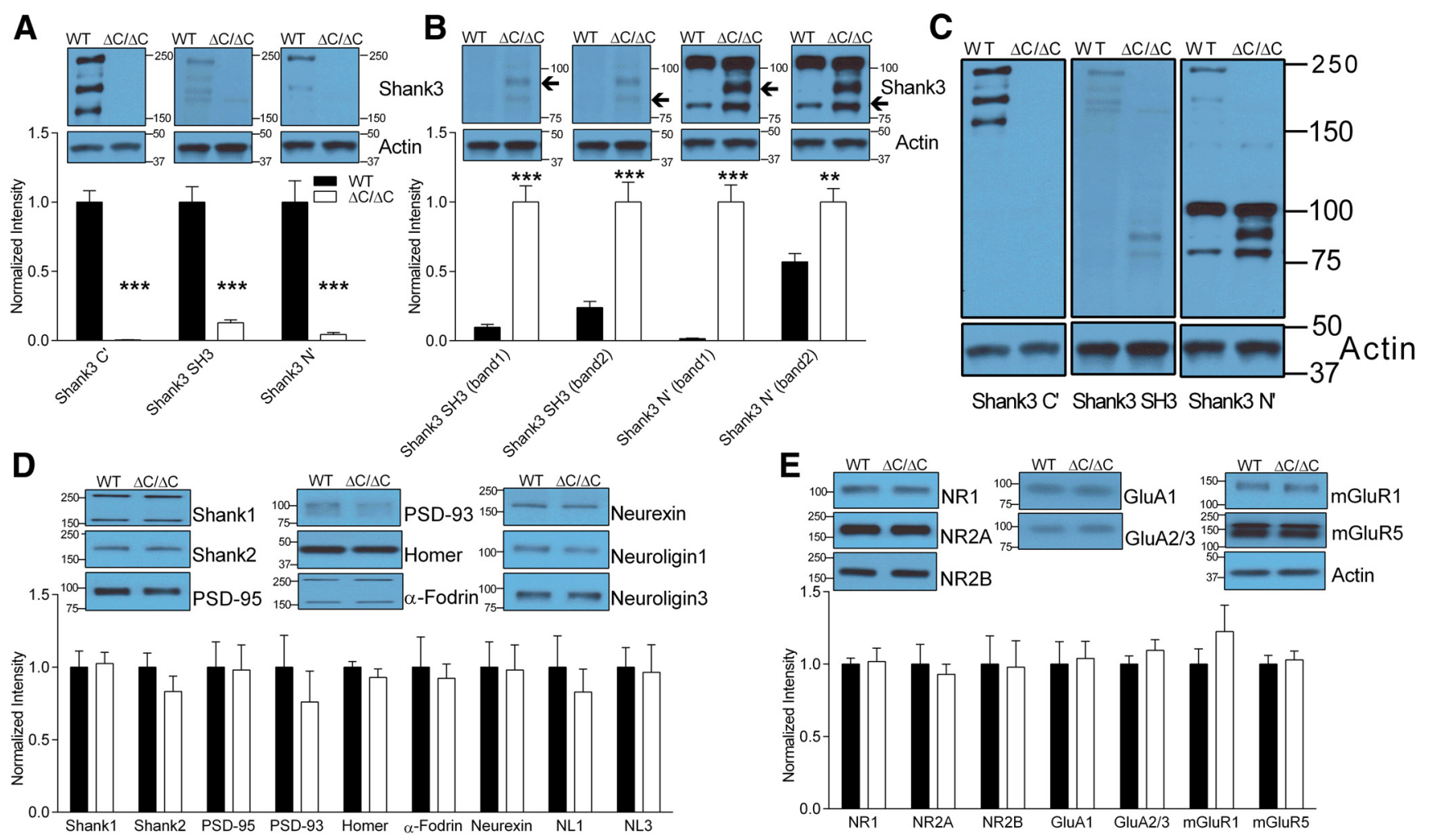

Figure 1. Loss of major naturally occurring Shank3 proteins in Shank $3^{\Delta C / \Delta C}$ mice. $A$, Quantification and representative Western blots of hippocampal lysates showing loss of the major isoforms of Shank3 with C' (P. Worley, JH3025), SH3 (Abcam), and N' (P. Worley) antibodies. B, Quantification and representative Western blots of lower-molecular-weight bands that appear or increase in intensity in the Shank $3^{\Delta C / \Delta C}$ hippocampal lysates using SH3 domain and N' antibodies. C, Larger representative Western blots showing the comparison of bands detected by the three Shank3 antibodies. D, E, Quantification and representative blots of whole hippocampus lysates with antibodies against PSD proteins and receptors that interact directly or indirectly with Shank3. In $\boldsymbol{A}, \mathbf{D}$, and $\boldsymbol{E}$, data are normalized to $\beta$-actin control and then to average of WT levels. In $\boldsymbol{B}$, data are normalized to $\beta$-actin control and then to average of Shank $3^{\Delta C / \Delta C}$. Error bars represent $S E M$, ${ }^{* *} p<0.01$, ${ }^{* * *} p<0.001$.

(Gong et al., 2012), we tested the Shank $3^{\Delta C / \Delta C}$ mice in the Morris water maze task, a test of spatial learning and memory. Shank $3^{\Delta C / \Delta C}$ mice were significantly impaired in spatial learning compared with WT littermate controls using latency to reach the hidden platform as a measure (Fig. $3 A$; three-way rmANOVA; main effect of genotype: $F_{(1,32)}=13.55, p<0.001$; main effect of day: $F_{(7,224)}=36.47, p<0.000001$; genotype $\times$ day interaction: $F_{(7,224)}=2.54, p<0.05$; for complete statistical results for all experiments, see Table 1). The increased latency to reach the hidden platform in Shank $3^{\Delta C / \Delta C}$ mice was not accounted for by overall differences in swim speed during training (Fig. $3 B$; threeway rmANOVA; main effect of genotype: $F_{(1,32)}=0.5, p=0.48$; main effect of day: $F_{(7,224)}=2.00, p=0.05$; genotype $\times$ day interaction: $\left.F_{(7,224)}=0.92, p=0.48\right)$. Interestingly, there was a significant genotype $\times$ sex interaction in swim speed (Table 1 ). ANOVA results revealed that the Shank $3^{\Delta C / \Delta C}$ female group had significantly higher swim speed during training compared with WT females (genotype $\times$ sex interaction; Table 1 ).

Not surprisingly, Shank $3^{\Delta C / \Delta C}$ mice also exhibited significantly decreased learning using distance traveled to reach the platform, a measure that eliminates swim speed as a confound (Fig. 3C; three-way rmANOVA; main effect of genotype: $F_{(1,32)}=$ 17.41, $p<0.001$; main effect of day: $F_{(7,224)}=41.61, p<$ 0.000001 ; genotype $\times$ day interaction: $\left.F_{(7,224)}=3.25, p<0.005\right)$. On the initial trials, Shank $3^{\Delta C / \Delta C}$ and WT littermates spent the same amount of time in thigmotaxis (swimming near the maze walls). As the WT mice learned, they progressed to alternative search strategies, whereas the Shank $3^{\Delta C / \Delta C}$ mice were slower to shift to alternative search strategies from the initial thigmotaxic strategy (Fig. 3D; three-way rmANOVA; main effect of genotype: $F_{(1,32)}=7.62, p<0.01$; main effect of day: $F_{(7,224)}=75.09, p<$ 0.000001 ; genotype $\times$ day interaction: $\left.F_{(7,224)}=2.41, p<0.05\right)$. These findings are consistent with a significant decrease in spatial learning in the Shank $3^{\Delta C / \Delta C}$ mice.

Although Shank $3^{\Delta C / \Delta C}$ mice were slower to learn the water maze task, their spatial memory performance was only somewhat affected during the initial probe trial. Both WT and Shank $3^{\Delta C / \Delta C}$ mice showed a significant preference for the target quadrant compared with all three other quadrants [Fig. 3E; three-way rmANOVA; main effect of genotype: $F_{(1,32)}=0.22, p=0.63$; main effect of quadrant: $F_{(3,96)}=33.49, p<0.000001$; genotype $\times$ quadrant interaction: $F_{(3,96)}=4.21, p<0.01$; planned comparisons for WT mice: TargetNW vs RightNE: $p<0.00001$; TargetNW vs LeftSW: $p<0.00001$; TargetNW vs OppositeSE: $p<0.00001$; planned comparisons for Shank $3^{\Delta C / \Delta C}$ mice: TargetNW vs RightNE: $p<0.02$; TargetNW vs LeftSW: $p<0.02$; TargetNW vs OppositeSE: $p<0.0001$ (SE indicates southeast, SW indicates southwest, NE indicates northeast, and NW indicates northwest)], indicating that both groups were able to recall a previously learned spatial strategy. However, there was a significant decrease in the percentage time Shank $3^{\Delta C / \Delta C}$ mice spent in the target quadrant and a significant increase in the percentage time spent in the opposite quadrant compared with WT littermates (planned comparisons for WT vs Shank $3^{\Delta C / \Delta C}$ mice: TargetNW: $p<0.01$; OppositeSE: $p<0.01$ ), suggesting that Shank $3^{\Delta C / \Delta C}$ mutants may not have learned as efficient a spatial strategy as their WT littermate counterparts. To examine this further, we analyzed the number of times the mice crossed the exact 
A
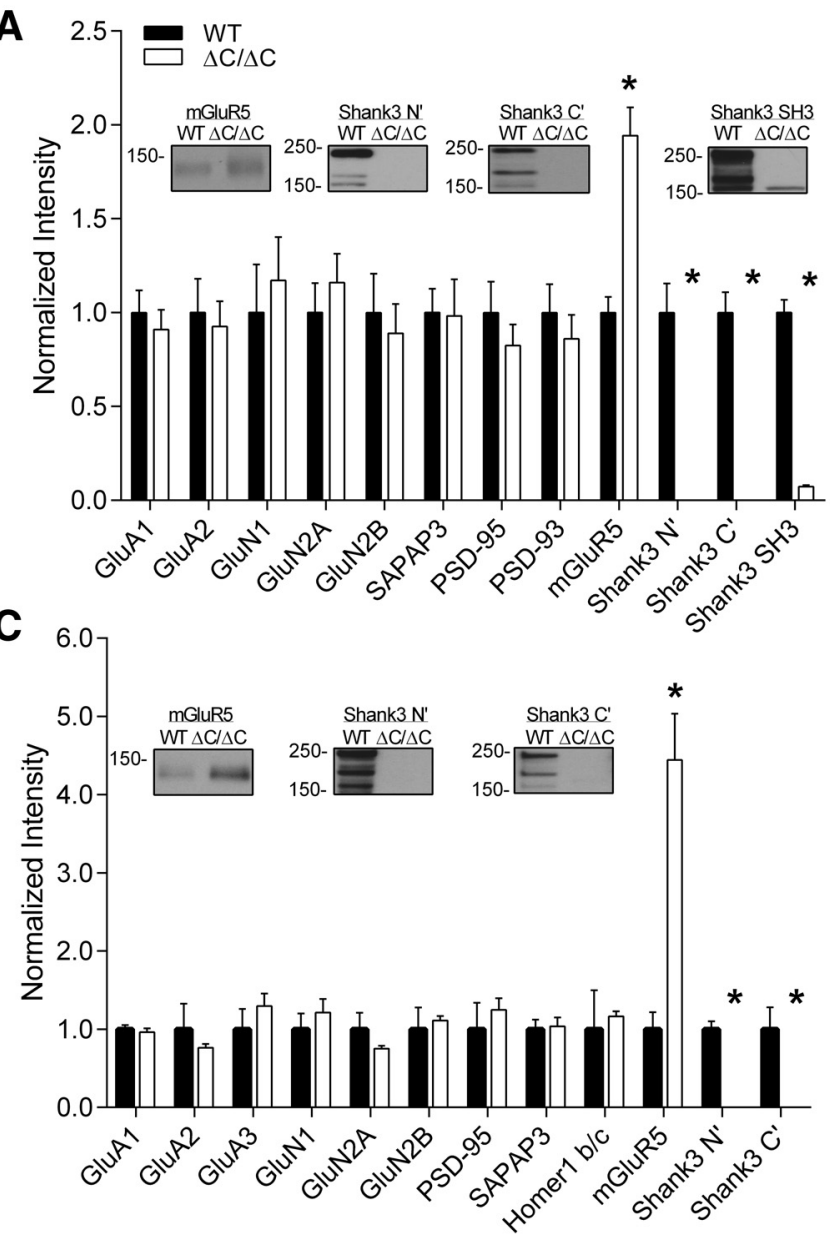

B

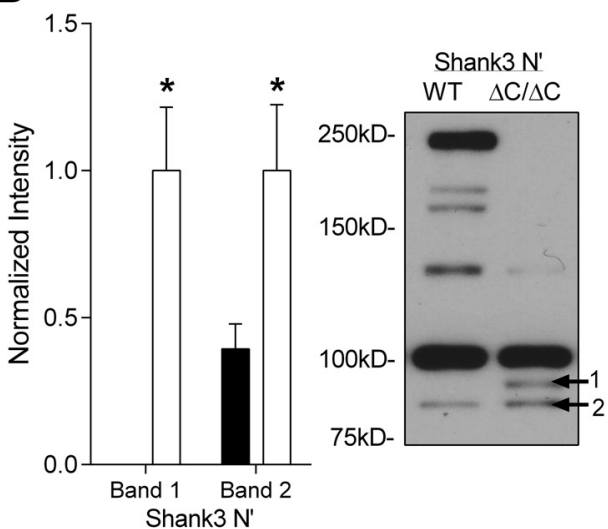

D
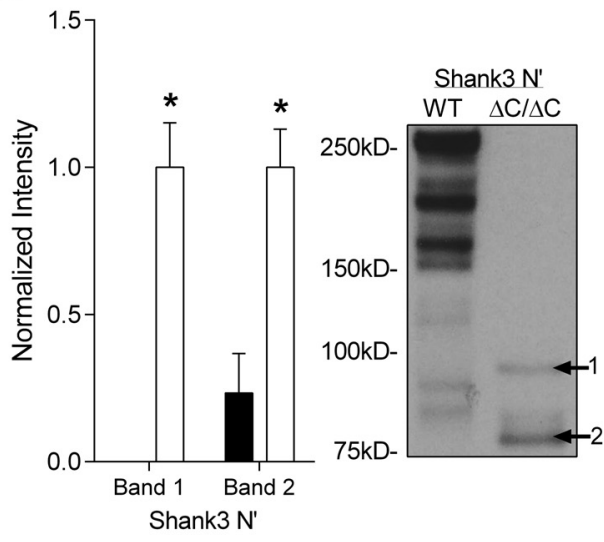

Figure 2. Increased mGluR5 protein levels in hippocampal synaptosome and PSDII fractions of Shank $3^{\Delta C / \Delta C}$ mice. A, Quantification of PSD proteins in synaptosome fractions of the hippocampus shows a complete loss of the major isoforms of Shank3 using the C terminus, $\mathrm{N}$ terminus, and SH3 domain antibodies against Shank3 in Shank $3^{\Delta C / \Delta C}$ mice $\left({ }^{*} p<0.0001\right)$ as well as an increase in mGluR5 ( $\left.{ }^{*} p<0.0001\right)$ compared with WT (WT, $n=8 ; \Delta C / \Delta C, n=6$ ). Representative blots are shown inset for proteins showing significant differences. $\boldsymbol{B}$, Quantification of the $<100 \mathrm{kDa}$ bands that appear or increase in the hippocampal synaptosomes of Shank $3^{\Delta C / \Delta C}$ mice. C, Quantification of PSD proteins in PSDII fractions of the hippocampus shows a complete loss of Shank3 using the C-terminal antibody $\left({ }^{*} p<0.05\right)$ as well as the N-terminal antibody $\left({ }^{*} p<0.001\right)$ of Shank3 in Shank $3^{\Delta C / \Delta C}$ mice as well as a robust increase in mGluR5 $\left({ }^{*} p<0.01\right)$ compared with WT (for each group, $n=3$ sets of hippocampi pooled from 2 mice each). $D$, Quantification and representative Western blot of the $<100 \mathrm{kDa}$ bands that appear or increase in the hippocampal PSDII fraction of Shank $3^{\Delta C / \Delta C}$ mice. For $\boldsymbol{A}-\boldsymbol{D}$, data were normalized to $\beta$-actin levels and then to the average of WT $(\boldsymbol{A}, \boldsymbol{C})$ or $\Delta C / \Delta C(\boldsymbol{B}, \boldsymbol{D})$. Data shown as average \pm SEM. Representative blots are shown inset for proteins showing significant differences.

target platform location and corresponding locations in the other three quadrants. Using this measure, only the WT group demonstrated a significant preference for the target platform location compared with the three other corresponding locations (Fig. 3F; threeway rmANOVA; main effect of genotype: $F_{(1,32)}=0.01, p=0.91$; main effect of quadrant: $F_{(3,96)}=13.00, p<0.000001$; genotype $\times$ quadrant interaction: $F_{(3,96)}=2.13, p=0.10$; planned comparisons for WT mice: TargetNW vs RightNE, $p<0.001$; TargetNW vs LeftSW, $p<0.01$; TargetNW vs OppositeSE, $p<0.0001$; planned comparisons for Shank $3^{\Delta C / \Delta C}$ mice: TargetNW vs RightNE, $p=$ 0.08 ; TargetNW vs LeftSW, $p=0.08$; TargetNW vs OppositeSE, $p=$ $0.052)$. Statistical analysis also demonstrated a genotype $\times$ sex interaction that, on closer analysis, suggests that the inability to show a preference for target platform location can be attributed to the Shank $3^{\Delta C / \Delta C}$ mutant males because, during the probe trial, they show a decrease in the number of platform location crosses (data not shown). Together, these data suggest that Shank $3^{\Delta C / \Delta C}$ mice are slower to learn a spatial strategy in the water maze compared with WT littermate controls.

To examine for both cognitive flexibility (Ozonoff and Jensen, 1999) and insistence on sameness (Schreibman, 1988; Greaves et al., 2006; Richler et al., 2007) as well as an additional test of spatial learning/memory, we performed a reversal learning experiment using the water maze, identifying additional evidence of significantly decreased spatial memory or cognitive inflexibility in Shank $3^{\Delta C / \Delta C}$ mice. The day after the first probe trial, mice were trained for 5 additional days with the hidden platform in the opposite quadrant. Interestingly, Shank $3^{\Delta C / \Delta C}$ mice showed no difference in acquisition of the reversal task using latency to reach the platform (Fig. 3G; three-way rmANOVA; main effect of genotype: $F_{(1,32)}=2.63, p=0.11$; main effect of day: $F_{(4,128)}=8.05$, $p<0.0009$; genotype $\times$ day interaction: $\left.F_{(4,128)}=1.69, p=0.15\right)$. Likewise, no differences were observed in swim speed (Fig. $3 \mathrm{H}$; three-way rmANOVA; main effect of genotype: $F_{(1,32)}=0.006$, $p=0.93$; main effect of day: $F_{(4,128)}=1.08, p=0.36$; sex $\times$ genotype interaction: $F_{(1,32)}=3.05, p=0.09$; genotype $\times$ day interaction: $\left.F_{(4,128)}=0.68, p=0.60\right)$, distance traveled to reach the platform (Fig. 3I; three-way rmANOVA; main effect of genotype: $F_{(1,32)}=2.08, p=0.15$; main effect of day: $F_{(4,128)}=4.99$, $p<0.0009$; genotype $\times$ day interaction: $\left.F_{(4,128)}=2.64, p<0.05\right)$, or the time spent in thigmotaxis (Fig. 3J; three-way rmANOVA; main effect of genotype: $F_{(1,32)}=2.29, p=0.13$; main effect of 
A

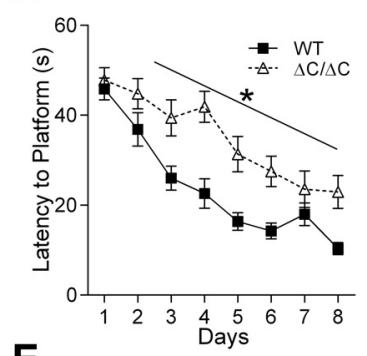

E

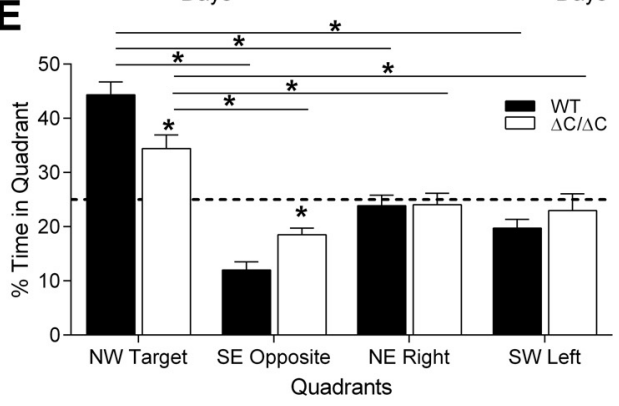

G

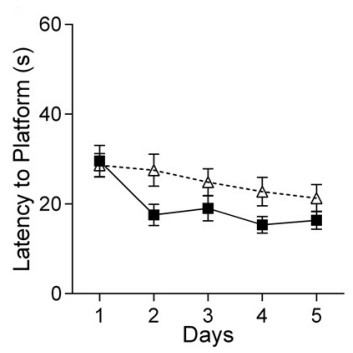

K

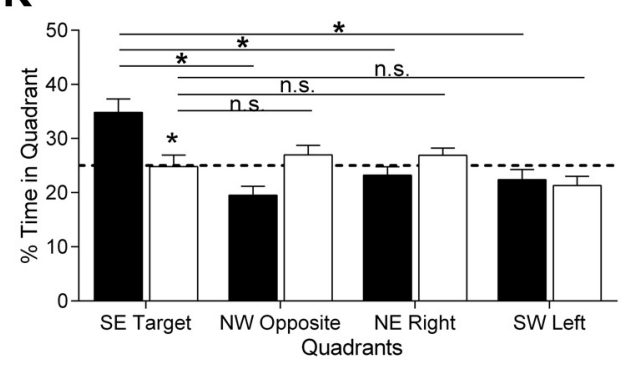

C

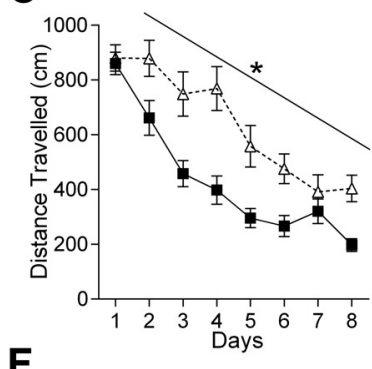

D

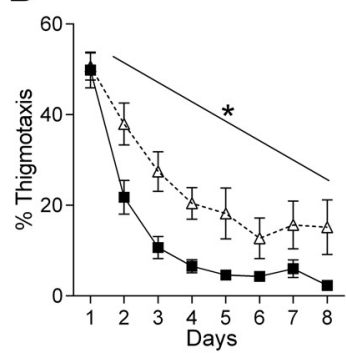

F
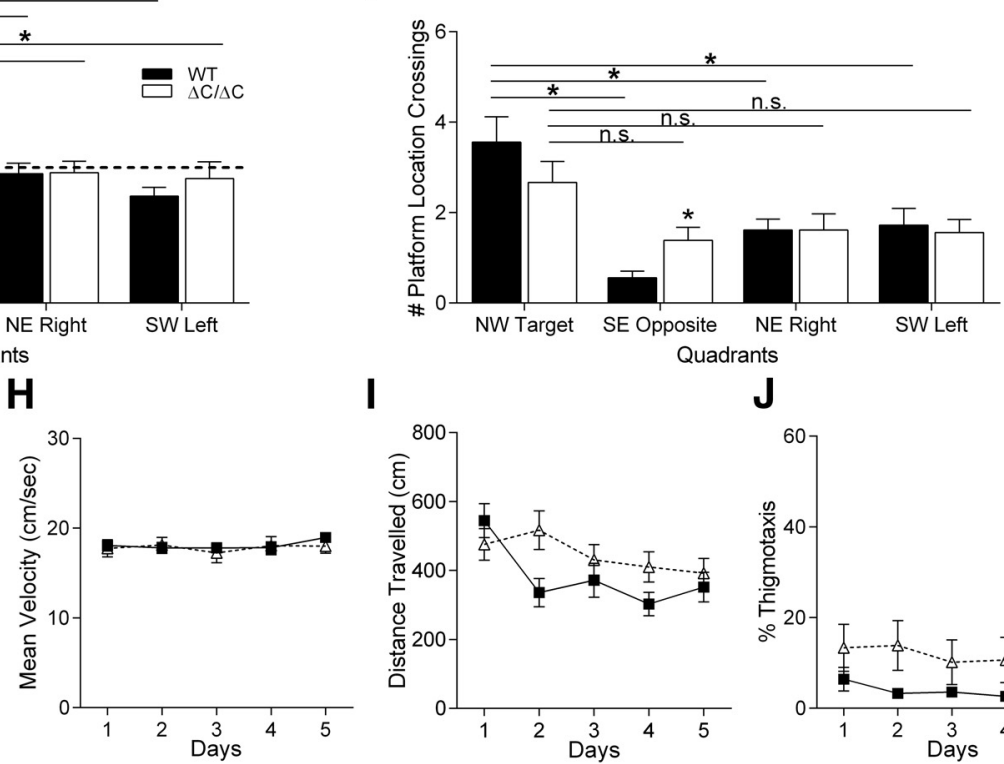

I

J
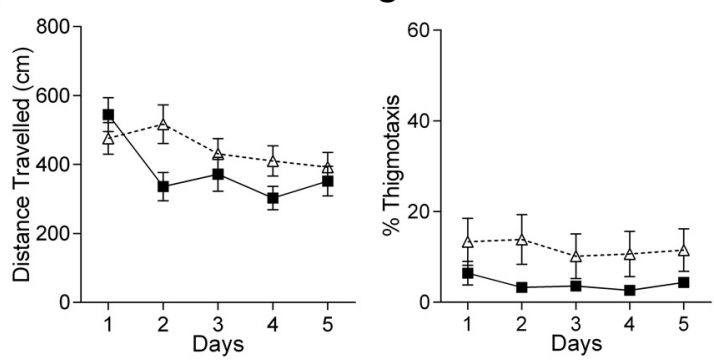

$\mathbf{L}$

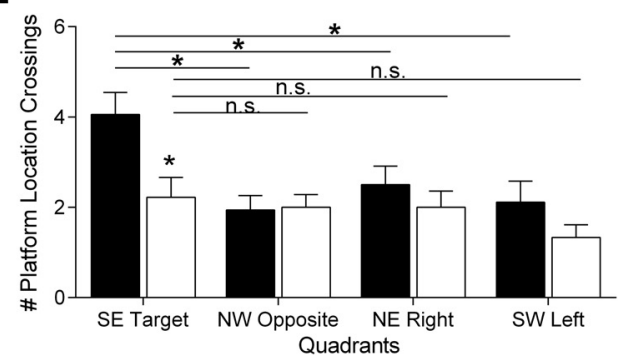

Figure 3. Shank $3^{\Delta C / \Delta C}$ mice exhibit impaired spatial learning. $\boldsymbol{A}-\boldsymbol{D}$, Training days for the Morris water maze task. For each day of training, data were averaged across four daily trials. $\boldsymbol{A}$, Latency to reach hidden platform on successive water maze days. Shank $3^{\Delta C / \Delta C}$ mice take longer to reach the submerged platform. $\boldsymbol{B}$, Swim speed on successive water maze training days. The average swim speed was unchanged in Shank $3^{\Delta C / \Delta C}$ mice. $C$, Distance traveled before reaching the hidden platform on successive water maze training days. Shank $3^{\Delta C / \Delta C}$ mice travel a more circuitous route (longer distance) before reaching the submerged platform. $\boldsymbol{D}$, Percentage time spent in thigmotaxis on successive water maze training days. $\boldsymbol{E}$, Time spent in target quadrant and other quadrants during probe trial in which target platform is removed. Shank $3^{\Delta C / \Delta C}$ mice spend more time in the target quadrant versus other quadrants but less time in target quadrant compared with littermate controls. $\boldsymbol{F}$, Number of target location crossings and corresponding phantom platform location crossings in other quadrants during the probe trial. Shank $3^{\Delta C / \Delta C}$ mice fail to show a preference for the target platform location. G-J, Training trials for the Morris water maze reversal task. No differences were observed during training for the Morris water maze reversal learning task in latency to platform $(\boldsymbol{G})$, mean swim speed $(\boldsymbol{H})$, distance traveled $(\boldsymbol{I})$, or thigmotaxis $(\boldsymbol{J}) . \boldsymbol{K}, 0$ n the probe trial for the Morris water maze reversal task, Shank $3^{\Delta C / \Delta C}$ mice failed to show preference for the target quadrant and spent equal time in all four quadrants. $L, O$ n the probe trial for the Morris water maze reversal task, Shank $3^{\Delta C / \Delta C}$ mice did not show preference for the target platform location $(n=$ 18 in all panels, data depicted as average \pm SEM, ${ }^{*} p<0.05$ ).

day: $F_{(4,128)}=1.50, p=0.20$; genotype $\times$ day interaction: $F_{(4,128)}=$ $0.57, p=0.68)$.

However, on the probe trial, Shank $3^{\Delta C / \Delta C}$ mice failed to show any preference for the new target location, whereas WT littermates showed a clear preference for the target quadrant compared with all other quadrants (Fig. $3 \mathrm{~K}$; three-way rmANOVA; main effect of genotype: $F_{(1,32)}=0.83, p=0.36$; main effect of quadrant: $F_{(3,96)}=5.87, p<0.01$; genotype $\times$ quadrant interaction: $F_{(3,96)}=6.51, p<0.001$; planned comparisons for WT mice: TargetSE vs RightNE, $p<0.001$; TargetSE vs LeftSW, $p<$
0.001; TargetSE vs OppositeNW, $p<0.0001$; planned comparisons for Shank $3^{\Delta C / \Delta C}$ mice: TargetSE vs RightNE, $p=0.55$; TargetSE vs LeftSW, $p=0.32$; TargetSE vs OppositeNW, $p=0.60$ ). Decreased spatial memory in the reversal learning task was confirmed using number of platform location crossings as a measure, with WT littermates demonstrating a clear preference for the target location over all other locations and the Shank $3^{\Delta C / \Delta C}$ mice showing no preference (Fig. $3 L$; three-way rmANOVA; main effect of genotype: $F_{(1,32)}=6.11, p<0.02$; main effect of quadrant: $F_{(3,96)}=4.93, p<0.01$; genotype $\times$ quadrant interaction: 
A

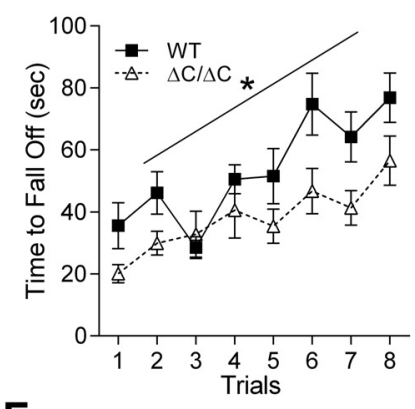

E

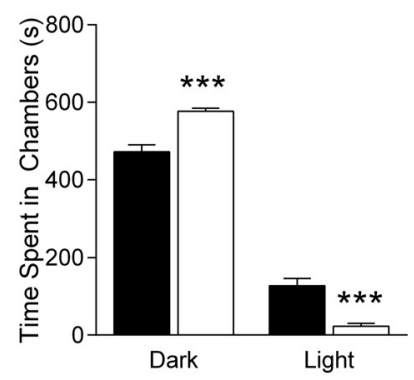

I

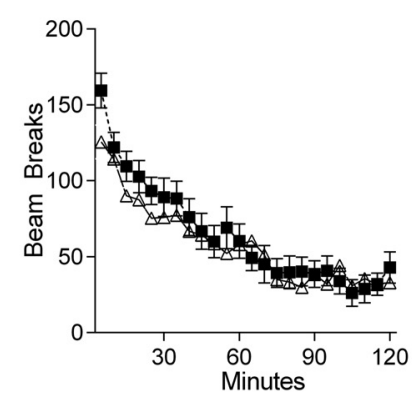

B

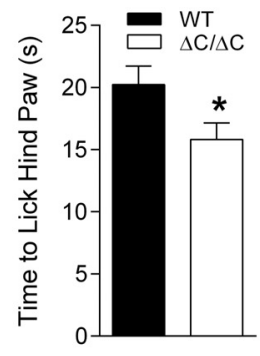

$\mathbf{F}$

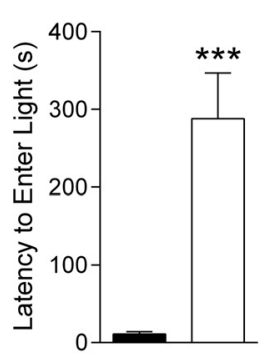

$\mathbf{J}$

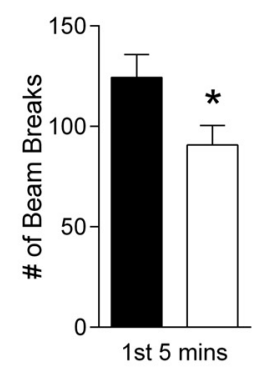

C

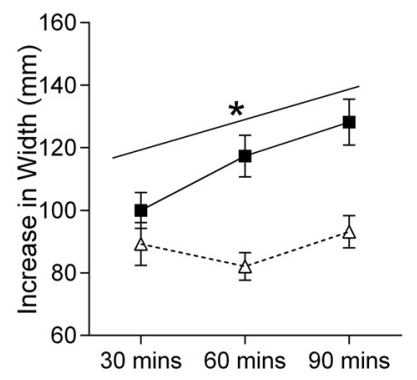

G

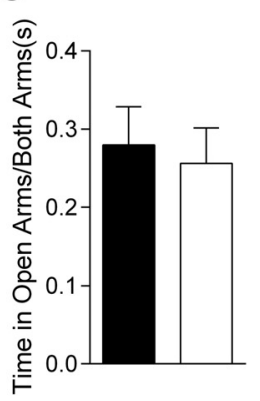

K

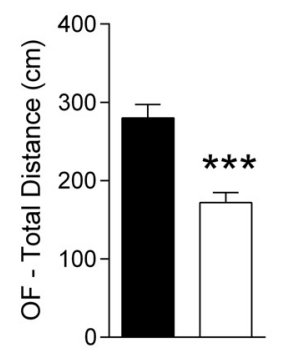

D

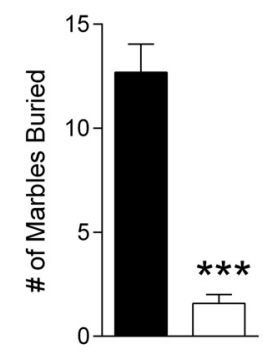

H

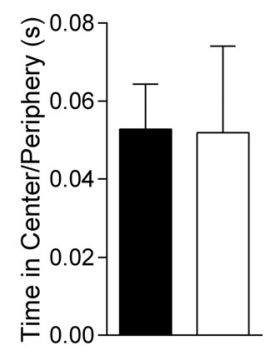

$\mathbf{L}$

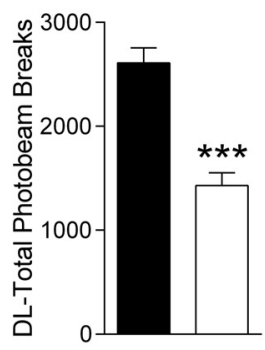

Figure 4. Shank $3^{\Delta C / \Delta C}$ mice exhibit impairments in other behavioral tasks. $A$, Latency to fall from or to go one full revolution on the rotarod task. Shank $3^{\Delta C / \Delta C}$ mice exhibit motor coordination impairments in eight trials of rotarod test conducted over $2 \mathrm{~d}(n=19)$. Legend in $\boldsymbol{A}$ applies to $\boldsymbol{C}$ and $\boldsymbol{I}$. $\boldsymbol{B}$, Latency to lick hindpaw on the hotplate task. Shank $3^{\Delta C / \Delta C}$ mice show hypersensitivity to heat on a hotplate $(n=18)$. Legend in $\boldsymbol{B}$ applies to $\boldsymbol{D}-\boldsymbol{H}$ and $\boldsymbol{J}-\boldsymbol{L}$. $\boldsymbol{C}$, Width of nest built as a function of time in a nest-building task. Shank $3^{\Delta C / \Delta C}$ mice exhibit impairments in nest-building behavior over a 90 min period $(n=19)$. D, Number of marbles buried during a 30 min marble-burying task. Shank $3^{\Delta C / \Delta C}$ mice show impaired marble burying behavior $(n=19)$. $\boldsymbol{E}$, Time spent in dark and light chambers during dark/light task. Shank $3^{\Delta c / \Delta C}$ mice spend more time in the dark than littermate controls $(n=19)$. $\boldsymbol{F}$, Latency to enter the light $c h a m b e r$ in the dark/light task. Shank $3^{\Delta C / \Delta C}$ mice exhibit dramatically increased latency to enter the light side $(n=19)$. $\mathbf{G}$, Fraction of time in the open arms versus time in other arms in the elevated plus maze task. Shank $3^{\Delta c / \Delta C}$ mice spend the same time in open versus closed arms when compared with littermate controls $(n=18)$. $\boldsymbol{H}$, Ratio of time spent in the center to time spent in the periphery in an open-field task. Shank $3^{\Delta C / \Delta C}$ mice behave the same as littermate controls $(n=19)$. I, Locomotor activity as measured by number of photobeam breaks during successive $5 \mathrm{~min}$ intervals over a $2 \mathrm{~h}$ period. Shank $3^{\Delta C / \Delta C}$ mice exhibit normal locomotor habituation over the full $2 \mathrm{~h}$ period $(n=19)$. J, Number of photobeam breaks during the initial 5 min of the locomotor task shown in $I$. Shank $3^{\Delta C / \Delta C}$ mice show decreased activity, initially suggesting abnormal locomotor response to novelty $(n=19)$. $\boldsymbol{K}$, Total distance traveled during the 10 min open-field task. Shank $3^{\Delta C / \Delta C}$ mice have decreased locomotor activity in the open field $(n=19) . L$, Number of photobeam breaks during the 10 min dark/light task. Shank $3^{\Delta C / \Delta C}$ mice have decreased locomotor activity in dark/light $(n=19)$. Error bars represent SEM, ${ }^{*} p<0.05$.

$F_{(3,96)}=1.98, p=0.12$; planned comparisons for WT mice: TargetSE vs RightNE, $p<0.05$; TargetSE vs LeftSW, $p<0.01$; TargetSE vs OppositeNW, $p<0.01$; planned comparisons for Shank $3^{\Delta C / \Delta C}$ mice: TargetSE vs RightNE, $p=0.66$; TargetSE vs LeftSW, $p=0.20$; TargetSE vs OppositeNW, $p=0.68$ ). These data are consistent with decreased spatial learning and memory and may or may not represent additional difficulties with cognitive flexibility or behavioral inflexibility. To test basic visual function and comprehension of the task, we measured latency and distance traveled to reach a visible cue atop the platform in the water maze. No significant differences were observed, but there was a trend toward increased latency and distance traveled to reach the visible cue.

\section{Homozygous Shank3 mutants have impaired motor} coordination

Shank $3^{\Delta C / \Delta C}$ mice exhibit impaired coordination on the accelerating rotarod. Shank $3^{\Delta C / \Delta C}$ mice had consistently decreased latencies to fall from the rotarod apparatus, although they demonstrated the same rate of motor learning indicated by improvement in their ability over subsequent trials (Fig. $4 A$; three-way rmANOVA; main effect of sex: $F_{(1,34)}=7.17, p<0.02$; main effect of genotype: $F_{(1,34)}=6.95, p<0.02$; main effect of trial: $F_{(7,238)}=11.71, p<0.000001$; sex $\times$ genotype interaction: $F_{(1,34)}=0.45, p=0.50$; sex $\times$ trial interaction: $F_{(7,238)}=0.51, p=$ 0.82 ; genotype $\times$ trial: $F_{(7,238)}=1.60, p=0.13$; sex $\times$ genotype $\times$ trial interaction: $\left.F_{(7,238)}=1.88, p=0.07\right)$. Interestingly, in addi- 
tion to the main effect of genotype, there was also a gender difference in performance that appeared to be attributable to the WT females because they were able to stay on the rotarod longer than the WT males (planned comparisons: females, WT vs Shank $3^{\Delta C / \Delta C}, p<0.05$; males, WT vs Shank3 ${ }^{\Delta C / \Delta C}, p=0.162$; WT, males vs females, $p<0.05$; Shank $3^{\Delta C / \Delta C}$, males vs females, $p=0.164)$.

\section{Shank3 mutant mice are hypersensitive in the hotplate task}

Some patients with Phelan-McDermid syndrome or 22q13 deletion syndrome are anecdotally said to have increased pain tolerance. Therefore, we tested the sensitivity of Shank $3^{\Delta C / \Delta C}$ mice to pain by testing the latency to lick the hindpaw on the hotplate task and found that it was decreased, suggesting a hypersensitivity to heat (Fig. 4B; two-way ANOVA; main effect of genotype: $F_{(1,32)}=$ 4.38, $p<0.05)$.

\section{Shank3 mutant mice exhibit an avoidance phenotype toward inanimate objects}

In attempts to measure nest building, marble burying, and other tasks, we uncovered an interesting avoidance of inanimate objects in the Shank $3^{\Delta C / \Delta C}$ mice. When we measured nest building by adding a nestlet to a novel cage after a habituation period, we found that Shank $3^{\Delta C / \Delta C}$ mice showed essentially no change in their nestlets, whereas WT littermates readily made nests from the material (Fig. $4 C$; three-way rmANOVA; main effect of genotype: $F_{(1,34)}=17.06, p<0.001$; main effect of time: $F_{(2,68)}=7.60$, $p<0.01$; genotype $\times$ time interaction: $\left.F_{(2,68)}=6.00, p<0.004\right)$. At first, we interpreted this as deficient nest building, but later tasks revealed a potential alternative explanation.

Surprisingly, similar avoidance behavior was observed in the marble-burying task. Shank $3^{\Delta C / \Delta C}$ mice showed little to no interest in burying marbles (Fig. 4D; two-way ANOVA; main effect of genotype: $\left.F_{(1,34)}=58.20, p<0.000001\right)$. In many instances, it appeared as if Shank $3^{\Delta C / \Delta C}$ mice did not even touch or walk over the marbles because they appeared completely undisturbed. A potentially related phenotype was observed in the three-chamber social interaction task wherein the Shank $3^{\Delta C / \Delta C}$ mice interacted significantly less with the inanimate object than WT littermate controls (see below and Fig. 5B).

We also tested Shank $3^{\Delta C / \Delta C}$ mice in anxiety behaviors and found that these mice show a remarkable increase in avoidance of the brightly lit chamber in the dark/light task. Shank $3^{\Delta C / \Delta C}$ mice spent almost the entire 10 min of this task in the dark chamber, virtually completely avoiding the brightly lit chamber (Fig. 4E; time spent in dark side, two-way ANOVA; main effect of genotype: $F_{(1,34)}=29.06, p<0.00006$; time spent in light side, twoway ANOVA; main effect of genotype: $F_{(1,34)}=29.06, p<$ $0.00006)$. This avoidance behavior is also evident by the increased latency to enter the brightly lit side of the box (Fig. 4F; two-way ANOVA; main effect of genotype: $\left.F_{(1,34)}=21.08, p<0.00006\right)$. Such behavior in this task is typically interpreted as an increase in anxiety-like behavior. To differentiate between increased anxiety-like behavior versus avoidance behavior, we tested Shank $3^{\Delta C / \Delta C}$ mice in two other standard tests for anxiety: elevated plus maze and open field. We did not observe an increase in anxiety-related behavior in the elevated plus maze because Shank $3^{\Delta C / \Delta C}$ mice and their WT littermate counterparts spent equal time in the open arms (Fig. 4G; two-way ANOVA; main effect of genotype: $\left.F_{(1,32)}=0.12, p=0.73\right)$. Similarly, no anxietylike phenotype was observed in the open-field task because the Shank $3^{\Delta C / \Delta C}$ mice spent the same amount of time in the center as their WT littermates (Fig. 4H; two-way ANOVA; main effect of genotype: $\left.F_{(1,34)}=0.003, p=0.95\right)$. Thus, it appears that Shank $3^{\Delta C / \Delta C}$ mice do not have an anxiety phenotype but demonstrate avoidance behavior in multiple tasks, including avoiding the brightly lit chamber in the dark/light box test.

\section{Shank3 mutant mice exhibit aberrant locomotor activity in response to novelty}

Curiously, in some tasks, but not others, Shank $3^{\Delta C / \Delta C}$ mice demonstrated decreased locomotor activity that can be interpreted as a transiently decreased locomotor response to novel situations. At first glance, when examining locomotor activity over $2 \mathrm{~h}$ in a novel home cage, Shank $3^{\Delta C / \Delta C}$ mice demonstrated completely normal locomotor activity (Fig. 4I; three-way rmANOVA; main effect of genotype: $F_{(1,34)}=0.49, p=0.48$; main effect of trial: $F_{(7,782)}=41.30, p<0.000001$; genotype $\times$ trial: $F_{(7,782)}=1.21$, $p=0.22)$. For the first $5 \mathrm{~min}$ in this novel home cage situation, however, the Shank $3^{\Delta C / \Delta C}$ mice showed a significant decrease in locomotor activity that reverted to the WT level rapidly thereafter (Fig. 4J; two-way ANOVA; main effect of genotype: $F_{(1,34)}=4.43$, $p<0.05)$. Along the same lines, distance traveled in the novel open-field arena over $10 \mathrm{~min}$ was decreased in Shank $3^{\Delta C / \Delta C}$ mice (Fig. $4 K$; two-way ANOVA; main effect of genotype: $F_{(1,34)}=$ 23.54, $p<0.00003$ ), and total number of photobeams interrupted during the $10 \mathrm{~min}$ in the dark/light chamber was decreased in Shank $3^{\Delta C / \Delta C}$ mice (Fig. $4 L$; two-way ANOVA; main effect of genotype: $\left.F_{(1,34)}=35.60, p<0.000002\right)$. We interpret these data overall as a decrease in locomotor response to novel environments that reverts rapidly to WT levels.

\section{Shank3 mutant mice exhibit minimal social interaction deficits}

Social interaction deficits are one of the three characteristic features of autism (Schreibman, 1988; Mahjouri and Lord, 2012). Therefore, we tested social behaviors in Shank $3^{\Delta C / \Delta C}$ mice in two separate tasks. Much like their WT littermate pairs, Shank $3^{\Delta C / \Delta C}$ mice showed no a priori preference for either side in the threechambered social interaction box before introduction of a social target (Fig. 5A; three-way rmANOVA: main effect of genotype: $F_{(1,30)}=1.23, p=0.27$; main effect of target: $F_{(1,30)}=0.01, p=$ 0.90 ; genotype $\times$ target interaction: $\left.F_{(1,30)}=0.06, p=0.80\right)$. Similarly, in the test for social versus inanimate preference, both WT and Shank $3^{\Delta C / \Delta C}$ spent more time interacting with the social target (Fig. $5 B$; three-way rmANOVA: main effect of genotype: $F_{(1,30)}=2.95, p=0.09$; main effect of target: $F_{(1,30)}=20.81, p<$ 0.0001 ; genotype $\times$ target interaction: $F_{(1,30)}=0.36, p=0.54$; planned comparisons, social vs inanimate: WT, $p<0.01$; Shank $\left.3^{\Delta C / \Delta C}, p<0.001\right)$. However, in the test of preference for social novelty versus familiarity, Shank $3^{\Delta C / \Delta C}$ mice showed no preference for social novelty, unlike their WT littermate pairs (Fig. $5 C$; three-way rmANOVA: main effect of genotype: $F_{(1,30)}=$ $0.56, p=0.45$; main effect of target: $F_{(1,30)}=4.16, p=0.05$; genotype $\times$ target interaction: $F_{(1,30)}=1.68, p=0.20$; planned comparisons for WT mice: social vs inanimate, $p<0.05$; planned comparisons for Shank $3^{\Delta C / \Delta C}$ mice: social vs inanimate, $p=0.23$ ).

No differences were observed in either social interaction or social learning during reciprocal social interaction with a juvenile (Fig. $5 D$; three-way rmANOVA; main effect of genotype: $F_{(1,32)}=$ 0.502, $p=0.48$; main effect of trial: $F_{(1,32)}=138.76, p<$ 0.000001 ; genotype $\times$ trial interaction: $F_{(1,32)}=3.88, p=0.05$; planned comparisons, initial vs recognition: WT, $p<0.00001$; Shank $3^{\Delta C / \Delta C}, p<0.00001$ ). 
A
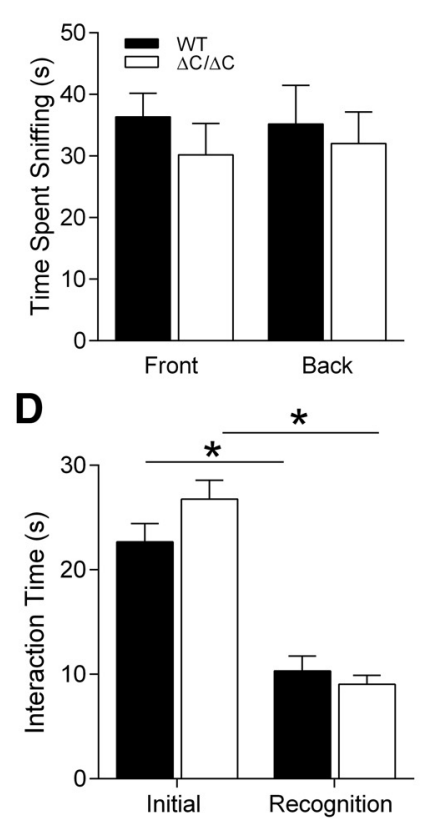

B

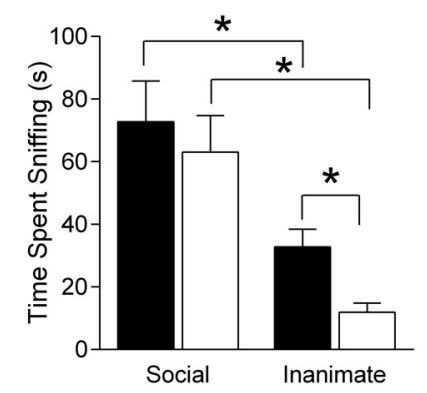

E

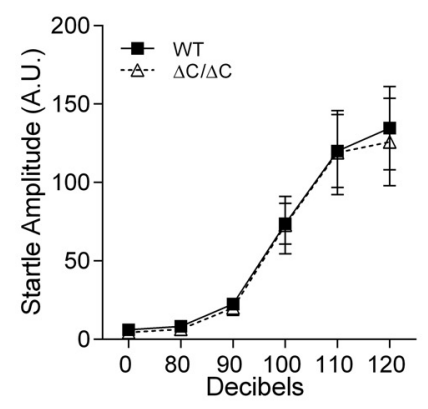

H

I
C

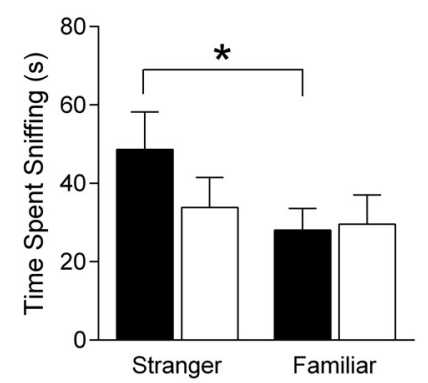

$\mathbf{F}$

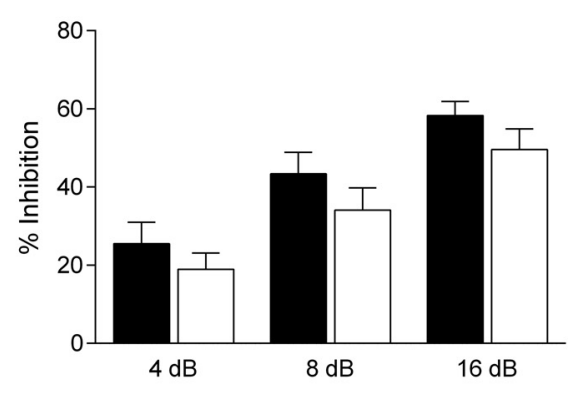

J
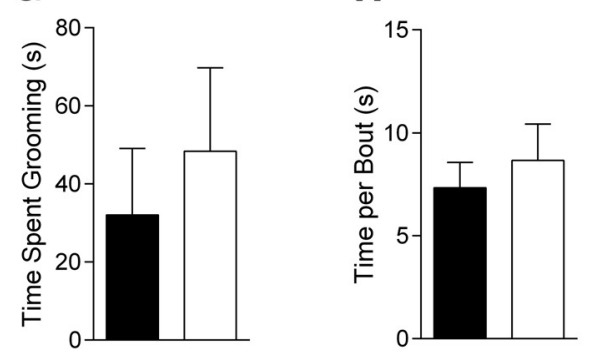

Figure 5. Shank $3^{\Delta C / \Delta C}$ mice exhibit minimal social interaction deficits and normal startle reactivity and PPI. A, Time spent in chambers with empty cages. For the first trial of three-chambered social interaction test, Shank $3^{\Delta C / \Delta C}$ mice were allowed to explore a three-chambered apparatus and showed no initial preference for either end of the box ( $n=17$ ). Legend in $\boldsymbol{A}$ applies to $\boldsymbol{B}-\boldsymbol{D}$ and $\boldsymbol{F} . \boldsymbol{B}$, In the second trial when given a choice between social or inanimate target, both WT and $S h a n k 3^{\Delta C / \Delta C}$ mice show a preference for a caged social target versus inanimate object. However, Shank $3^{\Delta C / \Delta C}$ mice avoided the inanimate object and spend less time sniffing it than the WT group $(n=17)$. $C$, In the third trial, when given a choice between novel social target versus a familiar social target, Shank $3^{\Delta c / \Delta C}$ mice failed to show a preference for the novel social target, unlike their WT littermate pairs $(n=17)$. $D$, Shank $3^{\Delta C / \Delta C}$ mice show normal social interaction with a juvenile conspecific mouse and, when presented with the same mouse $3 \mathrm{~d}$ later, exhibit normal social memory $(n=18)$. Shank $3^{\Delta C / \Delta C}$ mice exhibit normal response to startle $(\boldsymbol{E})$ and show no deficits in PPI $(\boldsymbol{E} ; n=18)$. Shank $3^{\Delta C / \Delta C}$ mice show no change in total time spent in repetitive grooming behavior $(\boldsymbol{G})$ or in time spent grooming per bout $(\boldsymbol{H} ; n=19)$. However, when tested at an older age, Shank $3^{\Delta C / \Delta C}$ mice show a significant increase in overall time spent grooming $(\boldsymbol{I})$ and time spent grooming per bout $(J ; n=16)$. Error bars represent SEM, ${ }^{*} p<0.05$.

Shank3 mutant mice exhibit normal startle response and PPI SHANK3 and other autism genes are implicated in schizophrenia (Burbach and van der Zwaag, 2009; Gauthier et al., 2009, 2010; Verpelli et al., 2012). Thus, we tested Shank $3^{\Delta C / \Delta C}$ mice for PPI deficits and auditory startle responses. We observed no differences in the auditory startle response at the tested sound levels (Fig. $5 E$; three-way rmANOVA; main effect of genotype: $F_{(1,32)}=$ $0.008, p=0.92$; main effect of trial: $F_{(5,160)}=34.95, p<0.0001$; genotype $\times$ decibel interaction: $\left.F_{(5,160)}=0.03, p=0.99\right)$. Similarly, there was no difference in PPI between the WT and Shank $3^{\Delta C / \Delta C}$ mice (Fig. $5 F$; three-way rmANOVA; main effect of genotype: $F_{(1,34)}=3.06, p=0.08$; main effect of trial: $F_{(2,64)}=$ $54.86, p<0.0001$; genotype $\times$ trial interaction: $F_{(2,64)}=0.20, p=$ 0.81 ). We did observe a significant interaction between sex and genotype, and additional analysis revealed that the Shank $3^{\Delta C / \Delta C}$ female mice show less PPI than Shank $3^{\Delta C / \Delta C}$ males or WT females (data not shown; for detailed statistics, see Table 1).

\section{Older, but not younger, Shank3 mutant mice exhibit} increased grooming

We characterized grooming behavior in $\operatorname{Shank} 3^{\Delta C / \Delta C}$, as a measure of the repetitive stereotyped behavior core symptom domain of autism. When tested at a younger age (9-18 weeks old), Shank ${ }^{\Delta C / \Delta C}$ mice did not exhibit an increase in total time spent grooming (Fig. $5 G$; two-way ANOVA; main effect of genotype: $\left.F_{(1,34)}=0.36, p=0.54\right)$. Similarly, no difference was observed in the time spent per grooming bout (Fig. $5 \mathrm{H}$; two-way ANOVA; main effect of genotype: $\left.F_{(1,34)}=0.44, p=0.50\right)$.

However, when grooming was tested in older mice (10-13 months old), Shank ${ }^{\Delta C / \Delta C}$ mutants exhibited a significant increase in grooming when compared with WT (Fig. 5I; two-way ANOVA; main effect of genotype: $\left.F_{(1,28)}=4.69, p<0.04\right)$. The older Shank $3^{\Delta C / \Delta C}$ mutants also showed an increase in time spent per grooming bout (Fig. 5J; two-way ANOVA; main effect of genotype: $\left.F_{(1,28)}=6.00, p<0.03\right)$. 

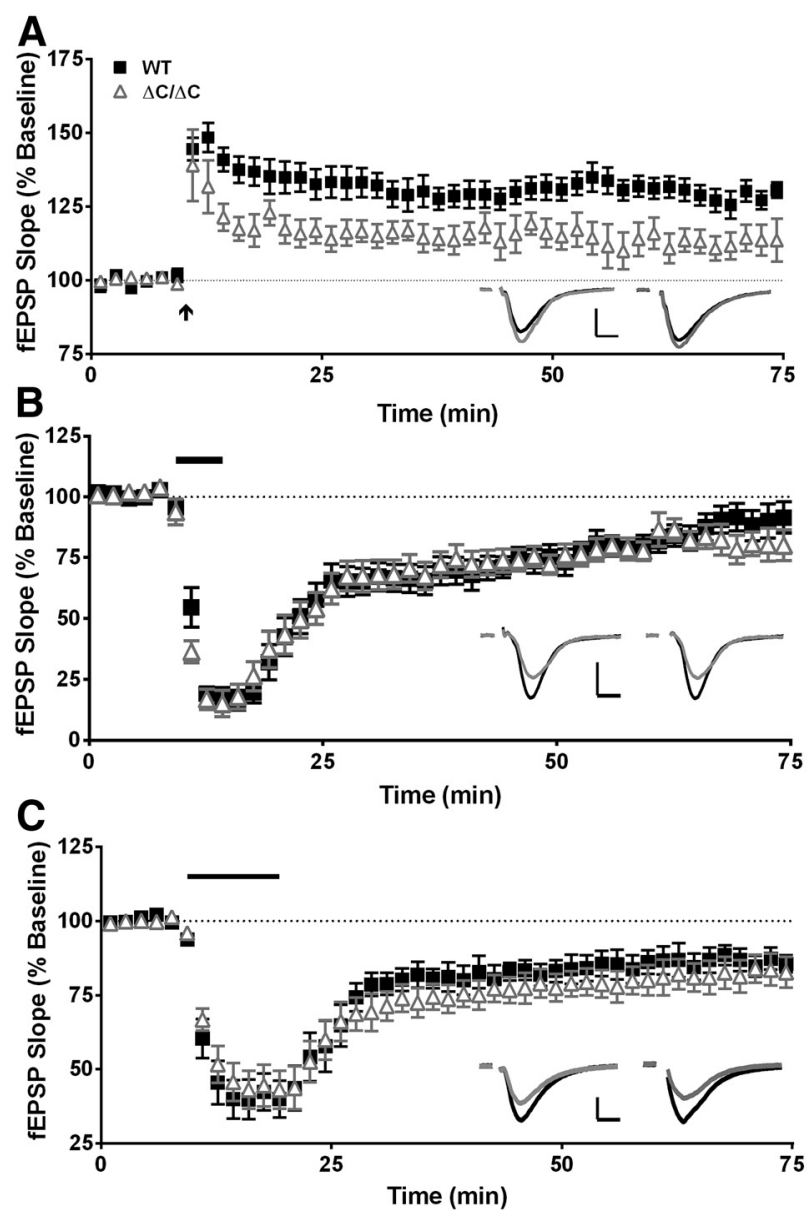

Figure 6. Synaptic plasticity at hippocampal CA3-CA1 synapses is altered in Shank $3^{\Delta C / \Delta C}$ mice. $A$, LTP is decreased in Shank $3^{\Delta c / \Delta C}$ mice $(n=6)$ compared with WT controls $(n=8)$. Arrow indicates onset of $100 \mathrm{~Hz}$ train for $1 \mathrm{~s}$. Inset, Average of 15 consecutive traces immediately before (black) and $60 \mathrm{~min}$ after (gray) $100 \mathrm{~Hz}$ tetanus. Calibration: $0.3 \mathrm{mV}$ (WT) or $0.55 \mathrm{mV}$ (Shank $3^{\Delta C / \Delta C}$ ), 5 ms. Legends in $A$ also apply to $B$ and $C . B$, mGluR-LTD from 6- to 8-week-old mice is not significantly affected by exon 21 deletion (WT, $n=9$; Shank $3^{\Delta C / \Delta C}, n=7$ ). Bar indicates 5 min bath application of DHPG. Inset, Average of 15 consecutive traces immediately before DHPG wash-in (black) and $60 \mathrm{~min}$ after the start of DHPG washout (gray). Calibration: $0.3 \mathrm{mV}, 5 \mathrm{~ms}$. C, There no significant difference in mGluR-LTD from 3- to 4-week-old Shank $3^{\Delta C / \Delta C}$ mice $(n=11)$ compared with WT $(n=9)$. Bar indicates $10 \mathrm{~min}$ bath application of DHPG. Inset, Average of 15 consecutive traces immediately before DHPG wash-in (black) and $60 \mathrm{~min}$ after the start of DHPG washout (gray). Calibration: $0.3 \mathrm{mV}$ (WT) or $0.22 \mathrm{mV}$ (Shank $3^{\Delta C / \Delta G}$ ), $5 \mathrm{~ms}$. Error bars represent SEM, ${ }^{*} p<0.05$.

Shank3 mutant mice do not exhibit communication deficits Communication deficits are also a hallmark of autism. To test communication, adult Shank $3^{\Delta C / \Delta C}$ mutant males were allowed to mate with free-roaming estrous females, and their USVs were recorded. No differences were observed in the latency to emit the first call or the total number of calls emitted in a 5 min recording period (data not shown; for statistical analysis, see Table 1).

\section{Shank3 mutant mice are impaired in hippocampal synaptic} transmission and plasticity

Because Shank $3^{\Delta C / \Delta C}$ mice exhibited significant deficits in hippocampus-dependent spatial learning, we examined long-term synaptic plasticity in the hippocampus. Extracellular "field" recordings made in the CA1 region of the hippocampus revealed a deficit in long-term plasticity (Fig. 6) that is consistent with the spatial learning deficits in Shank $3^{\Delta C / \Delta C}$ mice. LTP was significantly impaired in Shank $3^{\Delta C / \Delta C}$ mice compared with WT mice at 55-60 min after a 100 $\mathrm{Hz}, 1 \mathrm{~s}$ conditioning stimulus (Fig. $6 A$; WT, $127.2 \pm 3.64 \%, n=8$ vs Shank3 $\left.{ }^{\Delta C / \Delta C}, 112.1 \pm 4.08 \%, n=6 ; t_{(12)}=2.753, p=0.018\right)$.
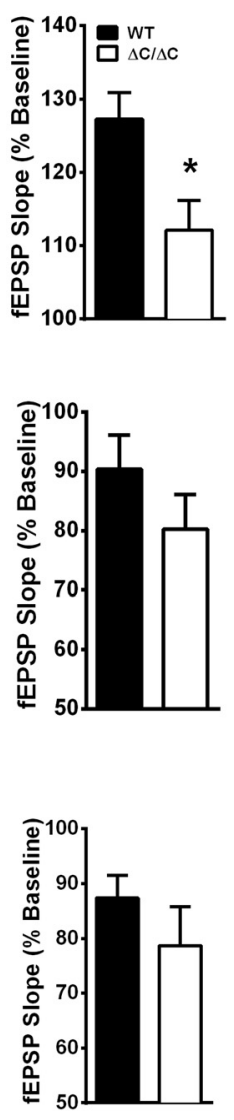

Shank3 also binds indirectly to group 1 mGluRs through interactions with Homer at the C-terminus proline-rich region ( $\mathrm{Tu}$ et al., 1999). Specifically, Shank3 has been shown to regulate mGluR5 signaling in hippocampal neuronal cultures, and knockdown of Shank3 in cultured neurons causes a decrease in mGluR5 signaling and mEPSC frequency (Verpelli et al., 2011). However, in our Shank $3^{\Delta C / \Delta C}$ homozygous mice, we identified a significant increase in mGluR5 in synaptosome and PSDII fractions (Fig. $2 A, C)$

To determine whether mGluR5 signaling is altered in Shank $3^{\Delta C / \Delta C}$ mice, we first induced mGluR-LTD using a $5 \mathrm{~min}$ bath application of the group I mGluR agonist DHPG $(100 \mu \mathrm{M})$ in 6- to 8-week-old mice. DHPG was used no more than $10 \mathrm{~d}$ after stock was prepared, and LTD experiments were performed with the experimenter blind to genotype and in an interleaved manner (alternating WT and mutant experiments) with no more than two slices per mouse. At 55-60 min after washout began (Fig. 6B), we found that modest LTD was induced in WT mice (90.36 \pm $5.73 \%, n=9)$ and in Shank $3^{\Delta C / \Delta C}$ mice $(80.24 \pm 5.84 \%, n=7)$, but no difference in percentage LTD between WT and Shank $3^{\Delta C / \Delta C}$ mice was observed $\left(t_{(18)}=\right.$ $0.996, p=0.243$ ). To optimize expression of mGluR-LTD, we repeated the experiment in 3- to 4 -week-old mice with a 10 min bath application of DHPG (Fig. 6C). With a larger sample size and doubling of DHPG application time, we again found no difference in mGluR-LTD between Shank $3^{\Delta C / \Delta C}$ mice and WT controls (WT, $87.38 \pm 4.14 \%, n=9$ vs Shank $3^{\Delta C / \Delta C}$, $78.67 \pm 7.12 \%, n=11 ; t_{(14)}=1.219, p=$ 0.332).

Because long-term plasticity is dependent on proper function of glutamatergic AMPARs and NMDARs and because Shank3 is known to interact indirectly with both types of receptors (Naisbitt et al., 1999; Uchino et al., 2006; Arons et al., 2012), we hypothesized that the relative contributions of AMPARs and NMDARs to the EPSC would be altered in Shank $3^{\Delta C / \Delta C}$ mice. As predicted, there was a significant decrease in the NMDA/AMPA ratio in Shank $3^{\Delta C / \Delta C}$ compared with WT mice (Fig. 7A; WT, $0.91 \pm 0.12, n=22$ vs Shank $3^{\Delta C / \Delta C}$, $\left.0.62 \pm 0.06, n=25 ; t_{(45)}=2.129, p=0.039\right)$.

In an effort to determine whether the decreased NMDA/ AMPA ratio was attributable to decreased NMDAR-mediated synaptic transmission or to increased AMPAR-mediated transmission, we examined the amplitude of spontaneous mEPSCs that primarily reflect AMPAR-mediated responses at individual synapses. Consistent with the NMDA/AMPA ratio decrease being attributable to decreased NMDAR-mediated responses, cumulative frequency of mEPSC amplitudes was not different in Shank $3^{\Delta C / \Delta C}$ mice compared with WT (Fig. 7B; KolmagorovSmirnov two-sample test, $p>0.1$ ). Similarly, mean mEPSC amplitude was not affected by Shank3 deletion (Fig. 7C; WT, 
A
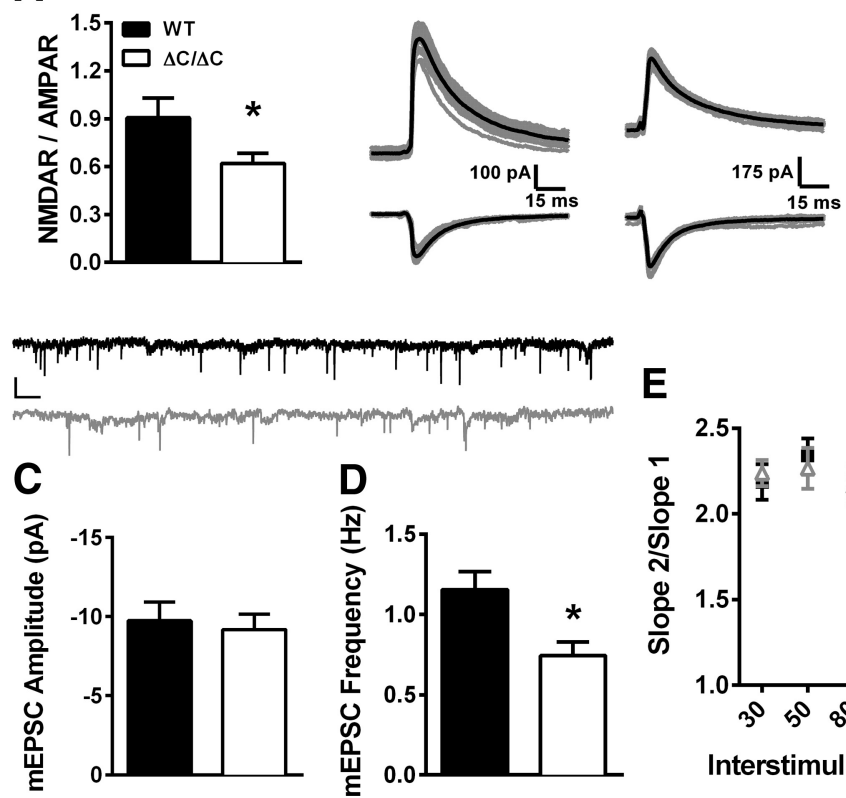

B

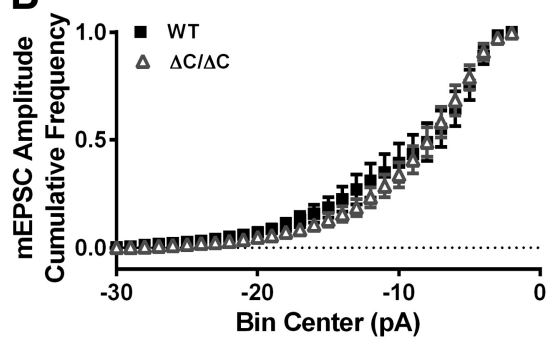

E

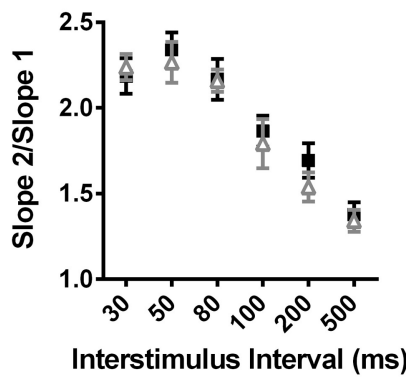

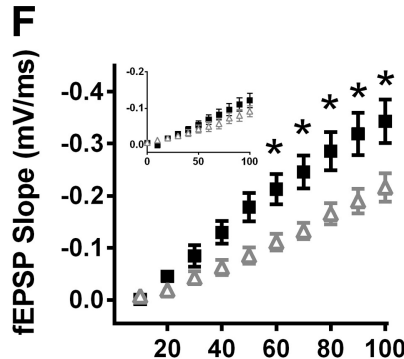

Stimulus Intensity $(\mu \mathrm{A})$

Figure 7. Synaptic transmission is altered at hippocampal CA3-CA1 synapses in Shank $3^{\Delta C / \Delta C}$ mice. $A$, The NMDA/AMPA ratio is decreased in Shank $3^{\Delta C / \Delta C}$ mice $(n=25) \operatorname{compared~with~WT~}(n=$ 22). Fifteen consecutive traces (gray) and average trace (black) at $-70 \mathrm{mV}$ (bottom) and at $+40 \mathrm{mV}$ (top) from WT mice (left) and $S h a n k 3^{\Delta C / \Delta C}$ mice (right). Legend in $\boldsymbol{A}$ applies to $\boldsymbol{C}$ and $\boldsymbol{D}$. Cumulative frequency of $\mathrm{mEPSC}$ amplitude $(\boldsymbol{B})$ and mean $\mathrm{mEPSC}$ amplitude ( $\boldsymbol{C}$ ) were unchanged, but mEPSC frequency $(\boldsymbol{D})$ was significantly decreased in $S_{\text {hank }}{ }^{\Delta C / \Delta C}$ compared with WT (WT, $n=$ 15; Shank $3^{\Delta C / \Delta C}, n=22$ ). Inset, One minute raw traces from a WT CA1 neuron (black) and a Shank $3^{\Delta C / \Delta C}$ CA1 neuron (gray). Calibration: 10 pA, 2.5 s. Legend in $\boldsymbol{B}$ also applies to $\boldsymbol{E}$ and $\boldsymbol{F}$. $\boldsymbol{E}$, PPR is not different between WT and Shank $3^{\Delta C / \Delta C}$ mice at interstimulus intervals of $30-500 \mathrm{~ms} . n=10$ for each genotype. $\boldsymbol{F}$, The relationship of stimulus intensity to fEPSP slope is decreased in Shank $3^{\Delta C / \Delta C}$ mice. Inset, Relationship of fiber volley to fEPSP slope is similar between WT and Shank $3^{\Delta C / \Delta C}$ mice. $n=10$ for each genotype. Error bars represent SEM, ${ }^{*} p<0.05$.

$-9.74 \pm 1.19 \mathrm{pA}, n=15$ vs Shank3 ${ }^{\Delta C / \Delta C}$,

$-9.19 \pm 0.97 \mathrm{pA}, n=22 ; t_{(35)}=0.364$, $p=0.718)$.

However, the frequency of mEPSCs was significantly decreased in Shank $3^{\Delta C / \Delta C}$ mice compared with WT (Fig. 7D; WT, $1.16 \pm$ $0.11 \mathrm{~Hz}, n=15$ vs Shank ${ }^{\Delta C / \Delta C}, 0.74 \pm 0.09$ $\left.\mathrm{Hz}, n=22 ; t_{(35)}=2.971, p=0.005\right)$. A decrease in mEPSC frequency can be attributable to a decrease in presynaptic evoked release probability $\left(P_{\mathrm{r}}\right)$, decreased synapse number, decreased synaptic release sites, or a selective decrease in spontaneous $P_{\mathrm{r}}$. To distinguish among these possibilities, we examined both paired pulse ratios (PPRs) and baseline synaptic strength via input/output (I/O) curves. Alterations in PPRs often accompany changes in presynaptic $P_{\mathrm{r}}$ (Zucker and Regehr, 2002; Lauri et al., 2007; Regehr, 2012), but we identified no changes in PPR using a broad range of interstimulus intervals (50-500 ms) in Shank $3^{\Delta C / \Delta C}$ mice compared with WT littermate controls (Fig. 7E; two-way rmANOVA; genotype: $F_{(1,107)}=0.748, p=0.389$; interstimulus interval: $F_{(5,107)}=$ 29.43, $p<0.0001$; genotype $\times$ interstimulus interval: $F_{(5,107)}=$ $0.254, p=0.937$; WT, $n=10$; Shank $\left.3^{\Delta C / \Delta C}, n=10\right)$. This finding is consistent with there being no change in evoked synaptic $P_{\mathrm{r}}$.

The I/O relationship of stimulus intensity to slope of the fEPSP was decreased in Shank $3^{\Delta C / \Delta C}$ mice (Fig. 7F; two-way rmANOVA; genotype: $F_{(1,18)}=8.969, p=0.008$; intensity: $F_{(10,180)}=93.93, p<$ 0.0001 ; intensity $\times$ genotype: $F_{(10,180)}=6.155, p<0.0001 ; \mathrm{WT}, n=$ 10 ; Shank $3^{\Delta C / \Delta C}, n=10$ ). Bonferroni's multiple comparisons indicate significant differences between WT and Shank $3^{\Delta C / \Delta C}$ mice at stimulus intensities $>50 \mu \mathrm{A}$, with a maximum fEPSP slope $36.9 \%$
B

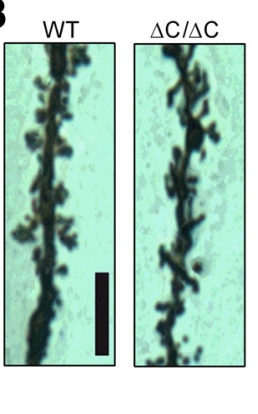

C

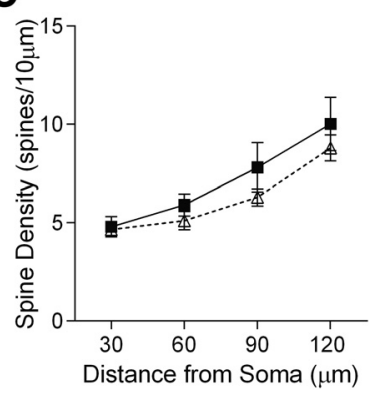

Figure 8. No morphological deficits were observed in the CA1 hippocampal neurons in Shank $3^{\Delta C / \Delta C}$ mice. $A$, No differences between genotypes were observed in quantitative assessment of branching via Sholl analysis. Legend in $\boldsymbol{A}$ also magnification. Scale bar, $5 \mu \mathrm{m}$ in WT (also applies to Shank $3^{\Delta C / \Delta C}$ ). $C$, No differences between genotypes were observed in spine density in the apical dendrites of CA1 hippocampus pyramidal neurons. $n=20$ neurons from 5 mice for each genotype. Error bars represent SEM, ${ }^{*} p<0.05$.

greater in WT compared with Shank $3^{\Delta C / \Delta C}$ mice (WT, $-0.34 \pm 0.04$ $\mathrm{mV} / \mathrm{ms}$; Shank $3^{\Delta C / \Delta C},-0.22 \pm 0.03 \mathrm{mV} / \mathrm{ms}$; Bonferroni's multiple comparisons, $p<0.0001)$. No difference was found between WT and Shank $3^{\Delta C / \Delta C}$ mice in the relationship between stimulus intensity and fiber volley amplitude (inset), suggesting no change in presynaptic axonal excitability (two-way rmANOVA; intensity: $F_{(10,280)}=$ 65.97, $p<0.0001$; genotype: $F_{(2,28)}=0.427, p=0.656$; intensity $\times$ genotype: $\left.F_{(20,280)}=0.936, p=0.542\right)$. These alterations in spontaneous and evoked synaptic transmission without changes in mEPSC amplitude suggest a possible decrease in the number of functional CA3-CA1 synapses to account for decreased LTP in Shank $3^{\Delta C / \Delta C}$ mice.

To determine whether a change in the number of structural synaptic spines is contributing to functional deficits in synaptic 
transmission and plasticity, we used Golgi-Cox staining and histology to see whether CA1 pyramidal neuron morphology is altered in the Shank $3^{\Delta C / \Delta C}$ mice. No differences were observed in dendritic complexity of the WT and Shank $3^{\Delta C / \Delta C}$ mice (Fig. $8 A$; two-way rmANOVA; main effect of genotype: $F_{(1,8)}=0.75, p=$ 0.41; main effect of distance from cell body: $F_{(9,74)}=58.82, p<$ 0.0001 ; genotype $\times$ distance interaction: $\left.F_{(9,74)}=0.57, p=0.81\right)$. Furthermore, no differences were observed in spine density between WT and Shank $3^{\Delta C / \Delta C}$ mice (Fig. $8 B, C$; rmANOVA; main effect of genotype: $F_{(1,8)}=1.01, p=0.34$; main effect of distance from cell body: $F_{(3,24)}=32.91, p<0.0001$; genotype $\times$ distance interaction: $\left.F_{(3,24)}=0.70, p=0.56\right)$. These findings were repeated in a separate cohort of mice at the younger age of P13-P17 as well to better correspond to the age at which the electrophysiological alteration in mEPSC frequency was observed. In P13P17 mice, we again found no significant difference in spine density between WT and Shank $3^{\Delta C / \Delta C}$ mice (data not shown). Therefore, changes in structural synaptic spine number do not appear to account for alterations in synaptic transmission and plasticity in Shank $3^{\Delta C / \Delta C}$ mice. However, it is possible that a more subtle difference in spine density exists that we may be underpowered to detect.

\section{Discussion}

Role of Shank3 in hippocampus-dependent learning and memory and synaptic transmission

We have identified multiple abnormalities in hippocampus function in a mouse model lacking major naturally occurring isoforms of Shank3. These mice exhibit decreased NMDARmediated synaptic transmission, decreased frequency of spontaneous glutamate release, and decreased evoked excitatory synaptic transmission with no change in short-term plasticity or mEPSC amplitude in area CA1 of the hippocampus. This decrease in NMDAR-mediated synaptic transmission is a likely cause of the observed decrease in LTP in the Shank $3^{\Delta C / \Delta C}$ mice. In turn, the LTP deficits are one potential explanation for the decreased hippocampus-dependent spatial learning abnormalities.

These abnormalities are most likely attributable to the loss of multiple naturally occurring isoforms of Shank3 in the Shank $3^{\Delta C / \Delta C}$ mutants. However, we cannot rule out the possibility that increases in smaller-molecular-weight forms of Shank3 that appear in the Shank $3^{\Delta C / \Delta C}$ mice on Western blot with $\mathrm{N}$-terminal and $\mathrm{SH} 3$ antibodies could be contributing to these abnormalities. The additional presence of these smallermolecular-weight isoforms in the Shan $k 3^{\Delta C / \Delta C}$ mutants is likely to occur in patients with autism caused by either translocation breakpoints or insertion mutations in exon 21 of Shank3, making them of potential relevance to a subset of autism associated with Shank3 mutations. Furthermore, the presence of additional novel isoforms of Shank3 has not yet been thoroughly evaluated in other published Shank3 mutant models (Bozdagi et al., 2010; Peça et al., 2011; Wang et al., 2011; Yang et al., 2012) and may also account for differences observed in these mutants. Indeed, it is not clear in these other Shank3 mutant models whether the phenotypes are attributable to loss of particular isoforms of Shank3 or to altered ratios of one isoform to another, much less whether novel isoforms appear as a result of these mutations. Mice lacking the entire Shank3 gene coding region will be of interest to compare with existing Shank3 mutant models to resolve these issues and as a model of the 22q13 deletion syndrome or Phelan-McDermid syndrome.

Both spatial learning deficits and decreased LTP in area CA1 of the hippocampus have also been reported in the
Shank $3^{e 4-9}$ homozygous mutant mice. This model lacks exons 4-9 coding for the ankryin repeat domain, resulting in loss of only the largest-molecular-weight isoform of Shank3 (SHANK3 $\alpha$; Wang et al., 2011). This finding suggests that loss of this largest isoform alone may be sufficient to produce altered spatial learning and decreased LTP in Shank3 mutants. The NMDA/AMPA ratio using whole-cell recordings was not reported in the Shank $3^{e 4-9}$ homozygous mutant mice. Similar to the present findings in Shank $3^{\Delta C / \Delta C}$ homozygotes, AMPARmediated synaptic transmission was intact in the Shank $3^{\text {e4-9 }}$ homozygous mutants as supported by no change in whole-cell mEPSC amplitude. It will be of interest to examine the NMDA/AMPA ratio directly in the Shank $3^{e 4-9}$ homozygous mutants to determine whether loss of only the largestmolecular-weight isoform of Shank3 is sufficient to decrease NMDAR-mediated synaptic transmission.

In addition, LTP deficits in area CA1 of the hippocampus have been reported in the Shank $3^{e 4-9}$ heterozygous mouse model (Bozdagi et al., 2010). However, in this case, extracellular field recording suggests no change in NMDAR-mediated synaptic transmission but rather a decrease in AMPARmediated transmission. Furthermore, whole-cell recording in the Shank $3^{e 4-9}$ heterozygotes demonstrated decreased mEPSC amplitude, consistent with a decrease in AMPA-mediated transmission as well as a dramatic increase in mEPSC frequency (Yang et al., 2012). The finding of extracellularly recorded decreases in both LTP and I/O curves were reproduced in a follow-up study by the same group, demonstrating the I/O curve differences in Shank $3^{e 4-9}$ homozygotes as well as heterozygotes (Yang et al., 2012) in conflict with a previous report (Wang et al., 2011). Again, the NMDA/AMPA ratio was not measured in whole-cell recordings. Also in the study by Yang et al., behavioral studies of Shank $3^{e 4-9}$ homozygous and heterozygous mice did not show a statistically significant difference in water maze learning in two, small, male-only cohorts, a finding that also contrasts with previously published work on Shank $3^{e 4-9}$ homozygotes (Wang et al., 2011) and the present study. The different findings in Shank $3^{\text {e4-9 }}$ homozygous mice I/O curves using extracellular field recordings (Wang et al., 2011; Yang et al., 2012) and in Shank $3^{\text {e4-9 }}$ homozygous water maze (Wang et al., 2011; Yang et al., 2012) remain to be resolved.

In yet another Shank3 homozygous mutant targeting exons 13-16 that code for the PDZ domain of Shank3 (Shank $3^{\text {e13-16 }}$ ) leading to loss of the two higher-molecular-weight isoforms of Shank3 (Shank3 $\alpha$ and Shank3 $\beta$ ), the minimal hippocampal electrophysiology performed highlights differences with the present findings in Shank $3^{\Delta C / \Delta C}$ homozygotes. This includes normal extracellularly recorded I/O curves measuring population spike amplitude rather than direct measurement of fEPSPs and no change in the amplitude or frequency of mEPSCs in area CA1 of hippocampus (Peça et al., 2011). Neither the NMDA/AMPA ratio nor LTP were measured in the hippocampus of Shank $3^{e 13-16}$ homozygous mutants (Peça et al., 2011). Curiously, the Shank $3^{e 13-16}$ homozygotes also did not show altered spatial learning in the water maze task with a small cohort of 4- to 5-week-old male mutants (Peça et al., 2011). This difference could be attributable to the different Shank3 mutation, different ages of mice tested, differences in protocols across laboratories, or differences in genetic background. Comparison of the multiple published Shank3 models within the same laboratory under the same conditions will be necessary to resolve these issues. 
Interestingly, despite a dramatic increase in mGluR5 in synaptic fractions, we find that mGluR-LTD is not significantly enhanced in Shank $3^{\Delta C / \Delta C}$ mice. Because group I mGluRs are currently being targeted as novel treatments for other mouse models of autism (Bear et al., 2004; Won et al., 2012; Yang et al., 2012) and Shank 3 has been shown to regulate mGluR5 expression and signaling in cultured neurons (Verpelli et al., 2011), additional functional studies of mGluR function in Shank3 mutants will be of critical importance.

\section{Shank 3 and social, repetitive, and communication behavior} Social deficits are one of the key diagnostic features of autism (Schreibman, 1988; Mahjouri and Lord, 2012), yet of the two social interaction tests that we administered, we only observed deficits in one trial of the three-chambered social interaction test in which Shank $3^{\Delta C / \Delta C}$ mice failed to show a preference for social novelty. This phenotype has been reported previously in Shank $3^{e 13-16}$ homozygotes (Peça et al., 2011) and Shank $3^{e 4-9}$ homozygotes (Wang et al., 2011). In the second test using social interaction with a juvenile, Shank $3^{\Delta C / \Delta C}$ mice did not show any deficits in initial interaction with juveniles or in a subsequent test of social memory. Together, these data suggest primarily intact social interaction with only minimal dysfunction in one task relevant to the social domain.

Surprisingly little phenotype was observed in the other two major behavioral symptoms domains relevant to autism, communication, and repetitive behaviors. An examination of USV during exposure of an adult male to an estrous female showed no changes in number of USVs or in latency to first USV in the Shank $3^{\Delta C / \Delta C}$ mice. Similarly, in younger mice, we observed no alteration in repetitive grooming behaviors. However, in older Shank $3^{\Delta C / \Delta C}$ mice, a significant increase in grooming behavior was observed. A thorough temporal/developmental assessment of the development of increased repetitive grooming and similar behaviors may be of interest in future studies.

\section{Shank 3 and associated features}

Aside from the three core diagnostic features, autism is also associated with motor-coordination impairments (Clarke, 1996; Abu-Dahab et al., 2012), and many patients with 22q13 deletion syndrome exhibit hypotonia and incoordination (Phelan and McDermid, 2012). Shank $3^{\Delta C / \Delta C}$ mice also show impairment in motor coordination but not in motor learning.

We also tested Shank $3^{\Delta C / \Delta C}$ mice in tests of anxiety because autism can be associated with anxiety disorders (Gillott et al., 2001). Of the three anxiety-related tasks, elevated plus maze, open field, and dark/light, we only found abnormalities in the dark/light task. Shank $3^{\Delta C / \Delta C}$ mice showed an increased latency to enter the light side and significantly preferred the dark chamber. Generally, this result alone might lead to a conclusion that Shank $3^{\Delta C / \Delta C}$ mice have increased anxiety. However, we did not see any differences in the other two anxiety tests. Thus, we interpret the avoidance of light in the dark/light task not as an increase in anxiety but as hypersensitivity to light or perhaps to novelty avoidance. We also tested Shank $3^{\Delta C / \Delta C}$ mice for acoustic startle response but found no differences. This suggests that Shank $3^{\Delta C / \Delta C}$ mice have hypersensitivity to only select sensory stimuli.

Some studies report that children with autism respond to novelty with avoidance behaviors (Kootz et al., 1982; Anckarsäter et al., 2006). Our Shank ${ }^{\Delta C / \Delta C}$ mice show a marked increase in avoidance of novel inanimate objects as evident in the results from nest-building and marble-burying behavior. Another aber- rant response to novelty in Shank $3^{\Delta C / \Delta C}$ mice is decreased initial locomotor response to a novel environment. This phenotype was only observed in the initial $5 \mathrm{~min}$ of exposure with rapid habituation to the locomotor apparatus thereafter. Interestingly, Shank $3^{\Delta C / \Delta C}$ mice also show a decreased latency to lick their hindpaw on a hotplate, indicating an increase in sensitivity to heat.

\section{Conclusions}

Recent studies strongly implicate SHANK3 in autism and Phelan-McDermid syndrome, making a thorough understanding of SHANK3 function in the CNS of critical importance. Our results indicate that Shank3 is critically important for normal synaptic transmission in the hippocampus and for normal spatial learning and memory. Loss of Shank3 leads to minimal social deficits but unveils multiple additional behavioral abnormalities, including motor coordination impairment, novelty avoidance, hypersensitivity to select sensory stimuli, and aberrant locomotor responses to novelty. Additional studies are needed to elucidate the underlying mechanisms of how Shank3 is involved in the above deficits, which brain regions are responsible for such deficits, and whether loss of Shank3 leads to irreversible neurodevelopmental abnormalities or to functional synaptic deficits that can be reversed later in life. Our findings of a decreased NMDA/AMPA ratio at hippocampal synapses and a dramatic increase in mGluR5 localization to synaptosome and PSD fractions suggests these as potential therapeutic targets for future preclinical studies.

\section{References}

Abu-Dahab SM, Skidmore ER, Holm MB, Rogers JC, Minshew NJ (2013) Motor and tactile-perceptual skill differences between individuals with high-functioning autism and typically developing individuals ages 5-21. J Autism Dev Disord 43:2241-2248. CrossRef Medline

Anckarsäter H, Stahlberg O, Larson T, Hakansson C, Jutblad SB, Niklasson L, Nydén A, Wentz E, Westergren S, Cloninger CR, Gillberg C, Rastam M (2006) The impact of ADHD and autism spectrum disorders on temperament, character, and personality development. Am J Psychiatry 163: 1239-1244. CrossRef Medline

Arons MH, Thynne CJ, Grabrucker AM, Li D, Schoen M, Cheyne JE, Boeckers TM, Montgomery JM, Garner CC (2012) Autism-associated mutations in ProSAP2/Shank3 impair synaptic transmission and neurexin-neuroliginmediated transsynaptic signaling. J Neurosci 32:14966-14978. CrossRef Medline

Bear MF, Huber KM, Warren ST (2004) The mGluR theory of fragile X mental retardation. Trends Neurosci 27:370-377. CrossRef Medline

Blundell J, Tabuchi K, Bolliger MF, Blaiss CA, Brose N, Liu X, Südhof TC, Powell CM (2009) Increased anxiety-like behavior in mice lacking the inhibitory synapse cell adhesion molecule neuroligin 2. Genes Brain Behav 8:114-126. CrossRef Medline

Blundell J, Kaeser PS, Sudhof TC, Powell CM (2010a) RIM1alpha and interacting proteins involved in presynaptic plasticity mediate prepulse inhibition and additional behaviors linked to schizophrenia. J Neurosci 30:5326-5333. CrossRef Medline

Blundell J, Blaiss CA, Etherton MR, Espinosa F, Tabuchi K, Walz C, Bolliger MF, Südhof TC, Powell CM (2010b) Neuroligin-1 deletion results in impaired spatial memory and increased repetitive behavior. J Neurosci 30:2115-2129. CrossRef Medline

Boccuto L, Lauri M, Sarasua SM, Skinner CD, Buccella D, Dwivedi A, Orteschi D, Collins JS, Zollino M, Visconti P, Dupont B, Tiziano D, Schroer RJ, Neri G, Stevenson RE, Gurrieri F, Schwartz CE (2013) Prevalence of SHANK3 variants in patients with different subtypes of autism spectrum disorders. Eur J Hum Genet 21:310-316. CrossRef Medline

Böckers TM, Mameza MG, Kreutz MR, Bockmann J, Weise C, Buck F, Richter D, Gundelfinger ED, Kreienkamp HJ (2001) Synaptic scaffolding proteins in rat brain. Ankyrin repeats of the multidomain Shank protein 
family interact with the cytoskeletal protein alpha-fodrin. J Biol Chem 276:40104-40112. CrossRef Medline

Bonaglia MC, Giorda R, Borgatti R, Felisari G, Gagliardi C, Selicorni A, Zuffardi O (2001) Disruption of the ProSAP2 gene in a $\mathrm{t}(12 ; 22)(\mathrm{q} 24.1$; $\mathrm{q} 13.3$ ) is associated with the 22q13.3 deletion syndrome. Am J Hum Genet 69:261-268. CrossRef Medline

Bonaglia MC, Giorda R, Mani E, Aceti G, Anderlid BM, Baroncini A, Pramparo T, Zuffardi O (2006) Identification of a recurrent breakpoint within the SHANK3 gene in the 22q13.3 deletion syndrome. J Med Genet 43:822-828. CrossRef Medline

Bozdagi O, Sakurai T, Papapetrou D, Wang X, Dickstein DL, Takahashi N, Kajiwara Y, Yang M, Katz AM, Scattoni ML, Harris MJ, Saxena R, Silverman JL, Crawley JN, Zhou Q, Hof PR, Buxbaum JD (2010) Haploinsufficiency of the autism-associated Shank3 gene leads to deficits in synaptic function, social interaction, and social communication. Mol Autism 1:15. CrossRef Medline

Burbach JP, van der Zwaag B (2009) Contact in the genetics of autism and schizophrenia. Trends Neurosci 32:69-72. CrossRef Medline

Clarke A (1996) Rett syndrome. J Med Genet 33:693-699. CrossRef Medline

Cohen RS, Blomberg F, Berzins K, Siekevitz P (1977) The structure of postsynaptic densities isolated from dog cerebral cortex. I. Overall morphology and protein composition. J Cell Biol 74:181-203. CrossRef Medline

Dhar SU, del Gaudio D, German JR, Peters SU, Ou Z, Bader PI, Berg JS, Blazo M, Brown CW, Graham BH, Grebe TA, Lalani S, Irons M, Sparagana S, Williams M, Phillips JA 3rd, Beaudet AL, Stankiewicz P, Patel A, Cheung SW, Sahoo T (2010) 22q13.3 deletion syndrome: clinical and molecular analysis using array CGH. Am J Med Genet A 152A:573-581. CrossRef Medline

Durand CM, Betancur C, Boeckers TM, Bockmann J, Chaste P, Fauchereau F, Nygren G, Rastam M, Gillberg IC, Anckarsäter H, Sponheim E, GoubranBotros H, Delorme R, Chabane N, Mouren-Simeoni MC, de Mas P, Bieth E, Rogé B, Héron D, Burglen L, Gillberg C, Leboyer M, Bourgeron T (2007) Mutations in the gene encoding the synaptic scaffolding protein SHANK3 are associated with autism spectrum disorders. Nat Genet 39: 25-27. CrossRef Medline

Etherton MR, Blaiss CA, Powell CM, Südhof TC (2009) Mouse neurexinlalpha deletion causes correlated electrophysiological and behavioral changes consistent with cognitive impairments. Proc Natl Acad Sci U S A 106:17998-18003. CrossRef Medline

Garner CC, Nash J, Huganir RL (2000) PDZ domains in synapse assembly and signalling. Trends Cell Biol 10:274-280. CrossRef Medline

Gauthier J, Spiegelman D, Piton A, Lafrenière RG, Laurent S, St-Onge J, Lapointe L, Hamdan FF, Cossette P, Mottron L, Fombonne E, Joober R, Marineau C, Drapeau P, Rouleau GA (2009) Novel de novo SHANK3 mutation in autistic patients. Am J Med Genet B Neuropsychiatr Genet 150B:421-424. CrossRef Medline

Gauthier J, Champagne N, Lafrenière RG, Xiong L, Spiegelman D, Brustein E, Lapointe M, Peng H, Côté M, Noreau A, Hamdan FF, Addington AM, Rapoport JL, Delisi LE, Krebs MO, Joober R, Fathalli F, Mouaffak F, Haghighi AP, Néri C, Dubé MP, Samuels ME, Marineau C, Stone EA, Awadalla P, Barker PA, Carbonetto S, Drapeau P, Rouleau GA; S2D Team (2010) De novo mutations in the gene encoding the synaptic scaffolding protein SHANK3 in patients ascertained for schizophrenia. Proc Natl Acad Sci U S A 107:7863-7868. CrossRef Medline

Gillott A, Furniss F, Walter A (2001) Anxiety in high-functioning children with autism. Autism 5:277-286. CrossRef Medline

Gong X, Jiang YW, Zhang X, An Y, Zhang J, Wu Y, Wang J, Sun Y, Liu Y, Gao X, Shen Y, Wu X, Qiu Z, Jin L, Wu BL, Wang H (2012) High proportion of 22q13 deletions and SHANK3 mutations in Chinese patients with intellectual disability. PloS One 7:e34739. CrossRef Medline

Greaves N, Prince E, Evans DW, Charman T (2006) Repetitive and ritualistic behaviour in children with Prader-Willi syndrome and children with autism. J Intellect Disabil Res 50:92-100. CrossRef Medline

Kootz JP, Marinelli B, Cohen DJ (1982) Modulation of response to environmental stimulation in autistic children. J Autism Dev Disord 12:185-193. CrossRef Medline

Kwon CH, Luikart BW, Powell CM, Zhou J, Matheny SA, Zhang W, Li Y, Baker SJ, Parada LF (2006) Pten regulates neuronal arborization and social interaction in mice. Neuron 50:377-388. CrossRef Medline

Lauri SE, Palmer M, Segerstrale M, Vesikansa A, Taira T, Collingridge GL
(2007) Presynaptic mechanisms involved in the expression of STP and LTP at CA1 synapses in the hippocampus. Neuropharmacology 52:1-11. CrossRef Medline

Mahjouri S, Lord CE (2012) What the DSM-5 portends for research, diagnosis, and treatment of autism spectrum disorders. Curr Psychiatry Rep 14:739-747. CrossRef Medline

Moessner R, Marshall CR, Sutcliffe JS, Skaug J, Pinto D, Vincent J, Zwaigenbaum L, Fernandez B, Roberts W, Szatmari P, Scherer SW (2007) Contribution of SHANK3 mutations to autism spectrum disorder. Am J Hum Genet 81:1289-1297. CrossRef Medline

Moy SS, Nadler JJ, Perez A, Barbaro RP, Johns JM, Magnuson TR, Piven J, Crawley JN (2004) Sociability and preference for social novelty in five inbred strains: an approach to assess autistic-like behavior in mice. Genes Brain Behav 3:287-302. CrossRef Medline

Nadler JJ, Moy SS, Dold G, Trang D, Simmons N, Perez A, Young NB, Barbaro RP, Piven J, Magnuson TR, Crawley JN (2004) Automated apparatus for quantitation of social approach behaviors in mice. Genes Brain Behav 3:303-314. CrossRef Medline

Naisbitt S, Kim E, Tu JC, Xiao B, Sala C, Valtschanoff J, Weinberg RJ, Worley PF, Sheng M (1999) Shank, a novel family of postsynaptic density proteins that binds to the NMDA receptor/PSD-95/GKAP complex and cortactin. Neuron 23:569-582. CrossRef Medline

Ozonoff S, Jensen J (1999) Brief report: specific executive function profiles in three neurodevelopmental disorders. J Autism Dev Disord 29:171-177. CrossRef Medline

Peça J, Feliciano C, Ting JT, Wang W, Wells MF, Venkatraman TN, Lascola CD, Fu Z, Feng G (2011) Shank3 mutant mice display autistic-like behaviours and striatal dysfunction. Nature 472:437-442. CrossRef Medline

Phelan K, McDermid HE (2012) The 22q13.3 deletion syndrome (PhelanMcDermid Syndrome). Mol Syndromol 2:186-201. CrossRef Medline

Powell CM, Schoch S, Monteggia L, Barrot M, Matos MF, Feldmann N, Südhof TC, Nestler EJ (2004) The presynaptic active zone protein RIMlalpha is critical for normal learning and memory. Neuron 42:143153. CrossRef Medline

Regehr WG (2012) Short-term presynaptic plasticity. Cold Spring Harbor Perspect Biol 4:a005702. CrossRef Medline

Richler J, Bishop SL, Kleinke JR, Lord C (2007) Restricted and repetitive behaviors in young children with autism spectrum disorders. J Autism Dev Disord 37:73-85. CrossRef Medline

Scattoni ML, Ricceri L, Crawley JN (2011) Unusual repertoire of vocalizations in adult BTBR $\mathrm{T}+\mathrm{tf} / \mathrm{J}$ mice during three types of social encounters. Genes Brain Behav 10:44-56. CrossRef Medline

Schreibman L (1988) Diagnostic features of autism. J Child Neurol [Suppl] 3:S57-S64. CrossRef Medline

Tabuchi K, Blundell J, Etherton MR, Hammer RE, Liu X, Powell CM, Südhof TC (2007) A neuroligin-3 mutation implicated in autism increases inhibitory synaptic transmission in mice. Science 318:71-76. CrossRef Medline

Tu JC, Xiao B, Naisbitt S, Yuan JP, Petralia RS, Brakeman P, Doan A, Aakalu VK, Lanahan AA, Sheng M, Worley PF (1999) Coupling of mGluR/ Homer and PSD-95 complexes by the Shank family of postsynaptic density proteins. Neuron 23:583-592. CrossRef Medline

Uchino S, Wada H, Honda S, Nakamura Y, Ondo Y, Uchiyama T, Tsutsumi M, Suzuki E, Hirasawa T, Kohsaka S (2006) Direct interaction of post-synaptic density-95/Dlg/ZO-1 domain-containing synaptic molecule Shank3 with GluR1 alpha-amino-3-hydroxy-5-methyl-4isoxazole propionic acid receptor. J Neurochem 97:1203-1214. CrossRef Medline

Verpelli C, Dvoretskova E, Vicidomini C, Rossi F, Chiappalone M, Schoen M, Di Stefano B, Mantegazza R, Broccoli V, Böckers TM, Dityatev A, Sala C (2011) Importance of Shank3 protein in regulating metabotropic glutamate receptor 5 (mGluR5) expression and signaling at synapses. J Biol Chem 286:34839-34850. CrossRef Medline

Verpelli C, Schmeisser MJ, Sala C, Boeckers TM (2012) Scaffold proteins at the postsynaptic density. Adv Exp Med Biol 970:29-61. CrossRef Medline

Wang X, McCoy PA, Rodriguiz RM, Pan Y, Je HS, Roberts AC, Kim CJ, Berrios J, Colvin JS, Bousquet-Moore D, Lorenzo I, Wu G, Weinberg RJ, Ehlers MD, Philpot BD, Beaudet AL, Wetsel WC, Jiang YH (2011) Synaptic dysfunction and abnormal behaviors in mice lacking major isoforms of Shank3. Hum Mol Genet 20:3093-3108. CrossRef Medline 
Wilson HL, Wong AC, Shaw SR, Tse WY, Stapleton GA, Phelan MC, Hu S, Marshall J, McDermid HE (2003) Molecular characterisation of the $22 \mathrm{q} 13$ deletion syndrome supports the role of haploinsufficiency of SHANK3/PROSAP2 in the major neurological symptoms. J Med Genet 40:575-584. CrossRef Medline

Wingate MMB, Kirby RS, Pettygrove S, Cunniff C, Meaney F, Schulz E, Miller L, Robinson C, Quintana G, Kaiser MY, Lee LC, Landa R, Newschaffer C, Constantino J, Fitzgerald R, Zahorodny W, Daniels J, Giarelli E, Pinto-Martin J, Levy SE, Nicholas J, Charles J, Zimmerman J, Maenner MJ, Durkin M, Rice C, Baio J, Van Naarden Braun K, Phillips K, Doernberg N, Yeargin-Allsopp M (2012) Prevalence of autism spectrum disorders-Autism and Developmental Disabilities Monitoring Network, 14 sites, United States, 2008. MMWR Surveill Summ 61:1-19. Medline
Won H, Lee HR, Gee HY, Mah W, Kim JI, Lee J, Ha S, Chung C, Jung ES, Cho YS, Park SG, Lee JS, Lee K, Kim D, Bae YC, Kaang BK, Lee MG, Kim E (2012) Autistic-like social behaviour in Shank2-mutant mice improved by restoring NMDA receptor function. Nature 486:261-265. CrossRef Medline

Yang M, Bozdagi O, Scattoni ML, Wöhr M, Roullet FI, Katz AM, Abrams DN, Kalikhman D, Simon H, Woldeyohannes L, Zhang JY, Harris MJ, Saxena R, Silverman JL, Buxbaum JD, Crawley JN (2012) Reduced excitatory neurotransmission and mild autism-relevant phenotypes in adolescent Shank3 null mutant mice. J Neurosci 32:6525-6541. CrossRef Medline

Zucker RS, Regehr WG (2002) Short-term synaptic plasticity. Annu Rev Physiol 64:355-405. CrossRef Medline 